\title{
Eine NeUe WirTSCHAFTSRÄUMLICHE GLIEDERUNG von Österreich: Aktualisierung einer ÖSTERREICh-AtLas-KarTe aus 1979
}

\author{
Huberta Kulmhofer und Albert Hofmayer, beide Wien*
}

mit 12 Abb. und 5 Tab. im Text sowie 2 farbigen Kartenbeilagen

Dem Andenken an Hans Bobek $(† 1990)$ gewidmet

\section{INHALT}

Summary 129

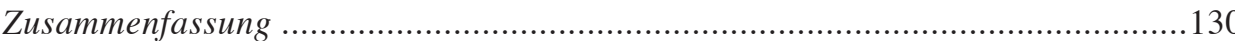

1 Einleitung ............................................................................ 131

2 Die wirtschaftsräumliche Gliederung Österreichs zum Stand 1971/73 ...........131

3 Die wirtschaftsräumliche Gliederung Österreichs zum Stand 2001 .................138

4 Resümee: Wichtigste Ergebnisse der vorliegenden Raumgliederung................162

5 Literaturverzeichnis ......................................................................... 164

\section{Summary}

A new economic regionalisation of Austria - update of a thematic map published 30 years ago in the 'Österreich-Atlas'

This paper presents a new subdivision of Austria into economic regions, comparing it to the map 'Economic regions on the basis of employment structure and workplace balance' published in 1979 in the 'Österreich-Atlas' (Atlas of the Republic of Austria). Using occupational and tourism statistics by communes, and following a method described in BOBEK \& HOFMAYER 1981, Austria is subdivided into approx. 200 regions of maximum homogeneity with respect to sector structure of employment, intensity of tourism and workplace balance. The new map was elaborated by Huberta KULMHOFER

\footnotetext{
* Mag. Dr. Huberta Kulmhofer, OMV AG, Corporate Project Management, Trabrennstraße 6-8, A-1020 Wien; E-Mail: huberta.kulmhofer@omv.com, http://www.omv.com; ao. Univ.-Prof. Dr. Albert HofMAYER, Wirtschaftsuniversität Wien, Institut für Wirtschaftsgeographie und Geoinformatik, Nordbergstraße 15 , A-1090 Wien; E-Mail: hofmayer@wu.ac.at, http://www.wu.ac.at/wgi
} 
(doctoral dissertation at the University of Economics Vienna, 2009).

After a short presentation of the new regionalisation, this paper focuses on two topics:

1) Critical check of H. BOBEK's findings derived from the map of 1979 concerning the spatial-structural model of the economic regions and the location tendencies of the main economic sectors (agriculture, manufacturing, services);

2) Cross-temporal comparison of spatial-economic structure of selected parts of Austria: central areas of the 'Länder', former agricultural areas, touristic areas.

Concerning (1) it is argued that BOBEK's spatial-structural model is still applicable to Austria's territory; nevertheless, a strong shift in the relative weight of the individual types of economic structure did occur, and a new structure type in the suburban zone of the large regional capitals emerged.

With respect to (2), for each of the three categories of economic structure two sample areas were selected (Vienna [Wien] - Linz; Waldviertel - South-eastern Austria; Salzburg - Carinthia [Kärnten]). By way of a visual comparison of the cross-temporal map pairs both similarities and dissimilarities of the spatial-structural development patterns are revealed, and suggestions made for further research.

\section{Zusammenfassung}

Der vorliegende Beitrag stellt eine neue wirtschaftsräumliche Gliederung Österreichs vor, die eine direkt vergleichbare Aktualisierung der im Jahre 1979 publizierten Österreich-Atlas-Karte „, Wirtschaftliche Strukturgebiete auf Grund der Arbeitsbevölkerung und Pendlerbilanz." darstellt. Auf Basis gemeindeweiser Beschäftigungs- und Tourismusdaten wird Österreich nach genau festgelegten Regeln (vgl. BOBEK \& HOFMAYER 1981) in wirtschaftsstrukturelle Regionen (ca. 200 Gebiete) gegliedert, die hinsichtlich Sektoralstruktur der Beschäftigten, Tourismusintensität und Arbeitsplatzausstattung möglichst homogen sind. Die neue Karte wurde im Rahmen einer Dissertation an der Wirtschaftsuniversität Wien von Huberta KULMHOFER (2009) erarbeitet.

Dieser Beitrag bietet nach einer kurzen Deskription der neuen Regionalisierung eine Auswertung in zweierlei Richtung:

1) Überprüfung der von H. Вовек aus der früheren Karte abgeleiteten Aussagen über das

Raummodell der Strukturgebiete und die Standorttendenzen der Wirtschaftssektoren;

2) Intertemporaler Vergleich der räumlich-sektoralen Struktur ausgewählter Wirtschaftsräume: Zentralräume, ehemalige Agrarräume, Tourismusräume.

Ad (1): Es wird ein prinzipielles Weiterbestehen des BовEK'schen Raumstrukturmodells der Hauptregionen Österreichs festgestellt, wobei sich aber das Gewicht der einzelnen Strukturtypen stark verschoben hat und ein völlig neuer Strukturtyp im Umland der Hauptregionszentren entstanden ist.

Ad (2): Aus den drei genannten Kategorien von Wirtschaftsräumen werden jeweils zwei Beispielsräume einander gegenübergestellt (Wien - Linz; Waldviertel-Südostösterreich; Salzburg - Kärnten). Mittels visuellen Vergleichs von intertemporalen Kartenpaaren werden sowohl Gemeinsamkeiten als auch Sonderentwicklungen der räumlichsektoralen Entwicklung aufgezeigt, welche Anregung für weitere Forschungen bieten. 


\section{Einleitung}

Aus Anlass des 20. Todestages von Hans BoвEK hat die Österreichische Kartographische Kommission der Österreichischen Geographischen Gesellschaft am 15. Juni 2010 in Wien eine Gedenkveranstaltung abgehalten. Dabei wurden durch Peter Jordan die kartographische Leistungen BoвeKs, speziell jene im Rahmen des „Atlas der Republik Österreich“, auch anhand von Kartenbeispielen gewürdigt. Eine der Österreich-AtlasKarten war die von Bовек gemeinsam mit dem zweitgenannten Autor dieses Beitrags im Jahr 1979 publizierte Karte „Wirtschaftliche Strukturgebiete auf Grund der Arbeitsbevölkerung und Pendlerbilanz“, welche auch in einem Textband der Reihe „Beiträge zur Regionalforschung“ erläutert wurde (Bовек \& HofMAYer 1981). Der Band enthält Aussagen über die Standorttendenzen und die Raumstruktur der Wirtschaft Österreichs.

Der vorliegende Beitrag stellt, nach einem knapp gehaltenen Überblick über die Hauptergebnisse der BoвEK-HofMAYER'schen Gliederung, eine neue wirtschaftsräumliche Gliederung Österreichs vor, die nach derselben Methodik wie damals von der erstgenannten Autorin dieses Beitrags im Rahmen einer wirtschaftsgeographischen Dissertation (Kulmhofer 2009) erarbeitet wurde. Der Schwerpunkt des Beitrages liegt auf der kritischen Überprüfung der damaligen theoriebezogenen Aussagen BoBEKs und auf dem Vergleich der räumlich-sektoralen Struktur ausgewählter österreichischer Wirtschaftsräume 1971/73 und 2001. Abschließend werden Möglichkeiten zur Weiterverwendung dieser Raumgliederung zur Diskussion gestellt.

\section{Die wirtschaftsräumliche Gliederung Österreichs zum Stand 1971/73}

\subsection{Angestrebte Ziele}

Im Vorwort der erwähnten Publikation schrieb Bовек: „Es handelt sich dabei um den Versuch, (...) die faktische räumlich-strukturelle Gliederung der österreichischen Wirtschaft in Standortseinheiten verschiedenen Charakters aufzudecken und darzustellen. (...) Dabei schwebte die Idee vor, ein räumliches Grundgerüst zu schaffen, mit dessen Hilfe man in Zukunft (...) nicht nur die Entwicklung der österreichischen Wirtschaft in ihrer räumlichen und sachlichen Differenzierung detaillierter erfassen, sondern darüber hinaus auch weitere, mit der Wirtschaft mehr oder minder eng verknüpfte Sachverhalte im Sinne der regionalen Disparitätenforschung mit Vorteil untersuchen könnte“ (Bobek \& Hofmayer 1981, S. V).

Der Altmeister der österreichischen Geographie strebte mit dieser Gliederung also an, ein räumliches Raster zur Verfügung zu stellen, das als Bezugsrahmen für die wirtschafts- und sozialgeographische Erforschung Österreichs dienen sollte.

Hierzu ist allerdings festzuhalten, dass die damals abgegrenzten Strukturgebiete das Ergebnis einer für den Stand 1971 bzw. 1973 durchgeführten Regionalisierung sind. Ein unverändertes Fortschreiben dieser Gliederung würde der seither abgelaufenen Dynamik der Wirtschaft und Gesellschaft nicht gerecht werden - abgesehen davon, 
dass es keine wissenschaftliche Leistung wäre, bereits feststehende Areale mit neuen Daten zu „füllen“. Daher wurde die aktuelle wirtschaftsräumliche Gliederung mit den neuestmöglichen Daten von Grund auf neu erstellt, aber nach derselben Methodik, sodass weitestgehende Vergleichbarkeit gegeben ist.

\subsection{Methodische Besonderheiten dieser Raumgliederung}

Die Bobek-Hofmayer'sche Raumgliederung ist das Ergebnis einer geographischkartographischen „Regionalisierung“. Dieser Terminus ist näher zu präzisieren, da er ebenso wie der Begriff „Region“ mehrdeutig ist. Bei den ausgegliederten Strukturgebieten handelt es sich weder um funktionale Regionen (wie z.B. zentralörtliche Bereiche oder Pendlerverflechtungsareale), noch um statistisch-administrative oder Programmregionen, sondern um homogene oder Struktur-Regionen. Diese sind laut B ARTELS 1975 durch die Merkmale maximale Ähnlichkeit innerhalb einer Region und maximale Unähnlichkeit zwischen Regionen gekennzeichnet. Derartige Regionen sollen (vgl. Johnston 1970, Sedlacek 1978, Openshaw \& Wymer 1995 u.a.) in einem zweistufigen Prozess gebildet werden: zunächst durch Klassifikation der räumlichen Basiseinheiten nach ihrer Ähnlichkeit (hier: Gemeindetypisierung), dann durch Zusammenfassung benachbarter ähnlicher Basiseinheiten (Aggregierung oder eigentliche Regionsbildung unter der Bedingung räumlicher Kontingenz).

Die Datenbasis bilden Gemeindeergebnisse der amtlichen Statistik, hauptsächlich der Volkszählung 1971, und zwar die Beschäftigten am Arbeitsort (Arbeitsbevölkerung, „AB“), gegliedert nach den drei Wirtschaftssektoren, sowie das Verhältnis zwischen $\mathrm{AB}$ und wohnhaften Beschäftigten (Pendlerbilanz). Beim Sekundärsektor erachteten die Autoren eine Differenzierung der „echten Industrie“ vom ubiquitär auftretenden „Gewerbe“ (verstanden gemäß dem österreichischen Sprachgebrauch als Handwerk) als unerlässlich für eine brauchbare wirtschaftsstrukturelle Typisierung (vgl. BовEK \& HofmaYer 1981, S. 6). Dies erfolgte anhand der Betriebsgröße laut Arbeitsstättenzählung 1973 („Gewerbe“: Arbeitsstätten mit <50 Beschäftigten, „Industrie“: Arbeitsstätten mit 50 und mehr Beschäftigten). Zur Differenzierung des Tertiärsektors wurden die AB im Gastgewerbe und darüber hinaus die Daten der Übernachtungen laut Fremdenverkehrsstatistik 1971 herangezogen.

In inhaltlicher Hinsicht wurden folgende Strukturtypen a priori festgelegt:

- Gebiete mit Dominanz-Strukturen (Vorherrschen eines einzelnen Wirtschaftssektors):

- Agrargebiete: Hauptkriterium $>40 \%$ der Arbeitsbevölkerung im Primärsektor;

- Industriegebiete: Sekundärsektor $>55 \%$ und Übergewicht von Industrie über Gewerbe;

- Zentren (Dienstleistungszentren): >40\% Tertiärsektor und Einpendlerüberschuss;

- Fremdenverkehrsgebiete: bedeutendes Gastgewerbe, hohe Nächtigungsintensität.

- Gebiete mit Meng-Strukturen: alle übrigen Gebiete.

Die genannten Schwellenwerte dienten als Grundlage der Gemeindetypisierung (erster Arbeitsschritt); nach erfolgter Aggregierung wurden sie im Zuge der Typisierung der 
Strukturgebiete geringfügig modifiziert und noch verfeinert (verschiedene Typen von Menggebieten); vgl. Abbildung 3.

Neben der Sektoralstruktur enthält die Karte zwei Zusatzaussagen für jedes Gebiet:

- Pendlerbilanz-Index, definiert als Arbeitsbevölkerung in \% der wohnhaften Beschäftigten;

- Tourismusintensität, definiert als Zahl der Nächtigungen pro 100 Einwohner.

In räumlicher Hinsicht war für die Aggregierung die Festlegung der Mindestgröße eines Strukturgebiets essentiell. Generell wurde diese bei einer Arbeitsbevölkerung von 5.000 (Summe der Arbeitsplätze) festgelegt. Für zwei Strukturtypen wurde die Mindestgröße allerdings nach anderen Kriterien bestimmt: Dominante Fremdenverkehrsgebiete sollten mindestens eine Million Übernachtungen aufweisen, und Gebiete mit starkem Auspendlerüberschuss eine Wohnbevölkerung von mindestens 12.500.

In diesem Zusammenhang ist zu erwähnen, dass die Bedingung der räumlichen Kontingenz nicht ausnahmslos angewandt wurde: In Fällen, wo eine bestimmte Struktur über kurze Distanz durch andersartige Struktur unterbrochen war, wurden mehrere räumlich getrennte Teile als ein Strukturgebiet ausgewiesen. Dadurch wurde erreicht, dass praktisch alle Strukturgebiete die erwähnte Mindestgröße besitzen (vgl. Beilage 1, Liste „Strukturgebiete Österreichs 1971“).

Nähere Begründungen der gewählten Schwellenwerte sowie Detailinformationen zur Operationalisierung finden sich in Bовек \& Hofmayer (1981, S. 6-32).

\subsection{Bовекs theoretische Aussagen über die Standorttendenzen der Wirtschaftssektoren und das Raummuster der Strukturgebiete ${ }^{1)}$}

\subsubsection{Standorttendenzen der Wirtschaftssektoren}

Die eigentlichen Bausteine der Strukturgebiete sind die jeweils vorhandenen Betriebe und deren Beschäftigte, gegliedert nach Sektoren. Daher können die Strukturgebiete als Ergebnis von Standortentscheidungen aufgefasst und interpretiert werden. BовEK (1981, S. 76-83) entwarf hierzu eine Theorie der Standorttendenzen der Wirtschaftssektoren in Österreich. Diese Theorie sei hier stichwortartig zusammengefasst (vgl. STÖHR 1983).

Der Primärsektor (Landwirtschaft) wird als Reliktphänomen gekennzeichnet, das im Lauf der Zeit immer mehr der ökonomisch mächtigeren Konkurrenz des Sekundärund Tertiärsektors weichen muss, selbst auf den Standorten mit den besten Böden.

Der Sekundärsektor hat im Verlauf seiner technischen und organisatorischen Entwicklung wiederholt seine Standorttendenzen gewechselt. Bовек unterscheidet vier Phasen:

1) Diese Aussagen finden sich in den Abschnitten 4.3.1 und 4.3.2 von Bobek \& Hofmayer (1981). Da diese zwei Abschnitte laut Vorwort von Hans BoBeK allein stammen, werden sie in diesem Beitrag als selbstständige Publikation (Bовек 1981) betrachtet. 
- vorindustrielle Phase: gewerbliche (= handwerkliche) Produktion, entweder an lokale Märkte oder an (bergbauliche) Rohstoffvorkommen gebunden;

- Manufakturzeit: Gründung einiger Großbetriebe in Städten (z.B. Tabakmanufakturen); Beginn der Heimindustrie im ländlichen Raum (z.B. Waldviertel), die Produkte an Verleger in Hauptstädten liefert;

- Hauptphase der Industrialisierung (Gründerzeit): Mit dem Aufkommen stark mechanisierter Betriebe wird die Nähe zur Energiequelle Kohle wichtigster Standortfaktor: Lage an Bahnlinien (Industrieachsen Wiener Becken, Mur-Mürz-Furche);

- Zweite Industrialisierungswelle nach 1945: Gründung von kapitalintensiven Konsum- und Investitionsgüterindustrien vor allem in den Landeshauptstädten und deren naher Umgebung. Kapitalextensive Industrien bleiben in Rohstoffnähe.

Die Standorttendenzen des Tertiärsektors sind für die zwei Teilsektoren unterschiedlich: Die zentralen Dienste, die zur Versorgung der umliegenden Bevölkerung dienen, konzentrieren sich gemäß der Christaller'schen Theorie der Zentralen Orte an den Verwaltungsmittelpunkten, hierarchisch gestuft nach Landes-, Viertels- und Bezirkshauptstädten.

Bei den Fremdenverkehrs-Dienstleistungen differenziert BовEK nach den drei Arten

- Freizeitfremdenverkehr (oder eigentlicher Tourismus, Standorttendenzen vgl. anschließend),

- Kurort- und Heilstättenverkehr - dieser ist an Heilquellen u.Ä. gebunden,

- Geschäftsverkehr - an Zentrale Orte gebunden.

Der eigentliche Tourismus hat Gebiete, die landwirtschaftlich wenig produktiv waren, zu hoher Produktivität entwickelt. Dabei sind in jüngerer Zeit hoch gelegene Alpengebiete, die Zweisaison-Tourismus ermöglichen, begünstigt; bereits ältere Tourismustradition weisen die Seengebiete am Alpenrand (Kärnten, Salzkammergut) auf.

\subsubsection{Modell der räumlichen Verteilung der wirtschaftlichen Strukturgebiete}

Als Sukkus aus der erarbeiteten wirtschaftsräumlichen Gliederung stellte BoBEK (1981, S. 83-87) die Existenz eines typischen Raummusters, gleichsam eine räumliche „Meta-Struktur“ der Strukturgebiete, fest.

Die Hauptregionen Österreichs - d.h. die historisch gewachsenen Länder - sind laut Вовек nicht nur funktionale Regionen im Sinne von Versorgungsbereichen (Einzugsbereiche der Zentralen Orte oberster Stufe), sondern besitzen auch eine regelhafte Ausstattung mit Gebieten bestimmter Wirtschaftsstruktur, welche sich außerdem regelhaft im Raum anordnen. Das BoBEK'sche Raummodell besteht aus zwei wirtschaftsstrukturellen Gebietskategorien: „Zentralraum“ und „Peripherie“. Diese zwei Kategorien sind wie folgt definiert:

Der ,Zentralraum“62) umfasst:

- das Hauptregionszentrum, meist ein dienstleistungsbetontes Zentrum,

\footnotetext{
2) Der von Bовек hier gebrauchte Begriff „Zentralraum“ ist eine reine Lage- und Strukturbezeichnung, er beinhaltet keine Verflechtungsaussage. In diesem Sinn wird der Begriff auch im vorliegenden Beitrag verwendet.
} 

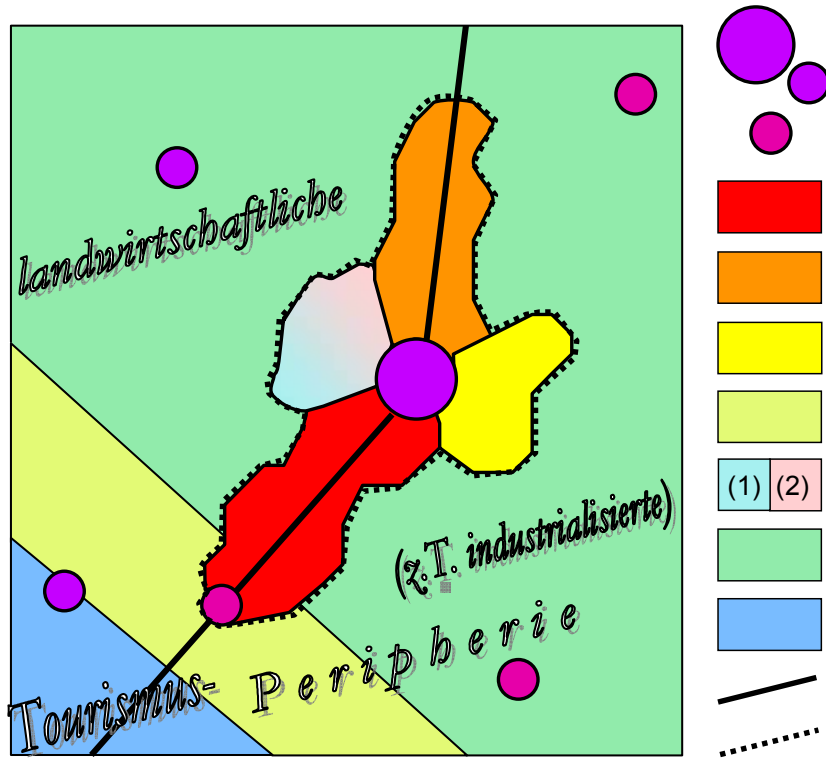

Typ I: Hauptregionszentrum bzw. weiteres dienstleistungsbetontes Zentrum Typ II: industriebetontes Zentrum

Typ III:

Industriegebiet

Typ IVa:

industriell-gewerbliches Menggebiet

Typ IVb:

industr.-gewerbl.-agrar. Menggebiet

Typ IVc:

agrarisch-gewerbliches Menggebiet

Typ IVd: dienstleistungsbet. Menggebiet

mit Auspendelcharakter (Wohngebiet)

Typ V:

Agrargebiet

Typ VI:

Fremdenverkehrsgebiet

Hauptverkehrsachse

Entwurf: Kulmhofer 2009. Anmerkung: Die sehr vielfältigen Strukturgebiete der Peripherie sind nur auszugsweise dargestellt.

Abb. 1: Raummodell der Wirtschaftsstruktur - „Zentralräume“ und „Peripherie“ - in Österreich, Stand 1971/73

- in seiner Nachbarschaft weitere Strukturgebiete intensiven Wirtschaftscharakters: eigentliche Industriegebiete und weitere industrialisierte Gebiete inklusive Sekundärzentren, vor allem entlang der Hauptverkehrsachse.

- Dazu kommt in der Regel auch ein prononciertes Wohngebiet (dienstleistungsbetontes Menggebiet mit starkem Auspendlerüberschuss, daher relativ geringer Arbeitsplatzdichte); ein derartiges Gebiet wird aber nur dann zum Zentralraum gerechnet, wenn es direkt an das Hauptregionszentrum angrenzt.

Die „Peripherie“ umfasst hingegen Gebiete mit extensiverer Wirtschaft und besitzt auch kaum Sekundärzentren, weil die vorhandenen Zentralen Orte nur selten die Mindestgröße eines Strukturgebiets erreichen. Wichtig ist die Zweiteilung in eine agrarische und eine Tourismus-Peripherie, wobei laut Bовек (1981) der Massentourismus bis dato auf inner- und randalpine Lagen beschränkt blieb.

Die Gültigkeit dieses Raummodells wurde von BobeK \& HofMAYER (1981, Kap. 4.3.3) für jede der sieben Hauptregionen Österreichs nachgewiesen. Eine graphische Darstellung des Modells ist allerdings im Textband nicht zu finden. Eine solche wurde erst von Huberta Kulmhofer (2009) entworfen (vgl. Abb. 1).

Die ganzseitige Abbildung 2 zeigt die zum damaligen Zeitpunkt festgestellten Realisierungen des Raummodells in den zentralen Teilen der Hauptregionen Österreichs: die Strukturgebiete mit Angabe des Typs und - als Maßzahl der Wirtschaftsintensität - ihre Arbeitsplatzdichte. Letztere wird nicht auf die Gesamtfläche, sondern auf den „Dauersiedlungsraum“ bezogen, der für Österreich eine geeignetere Vergleichsbasis darstellt. 


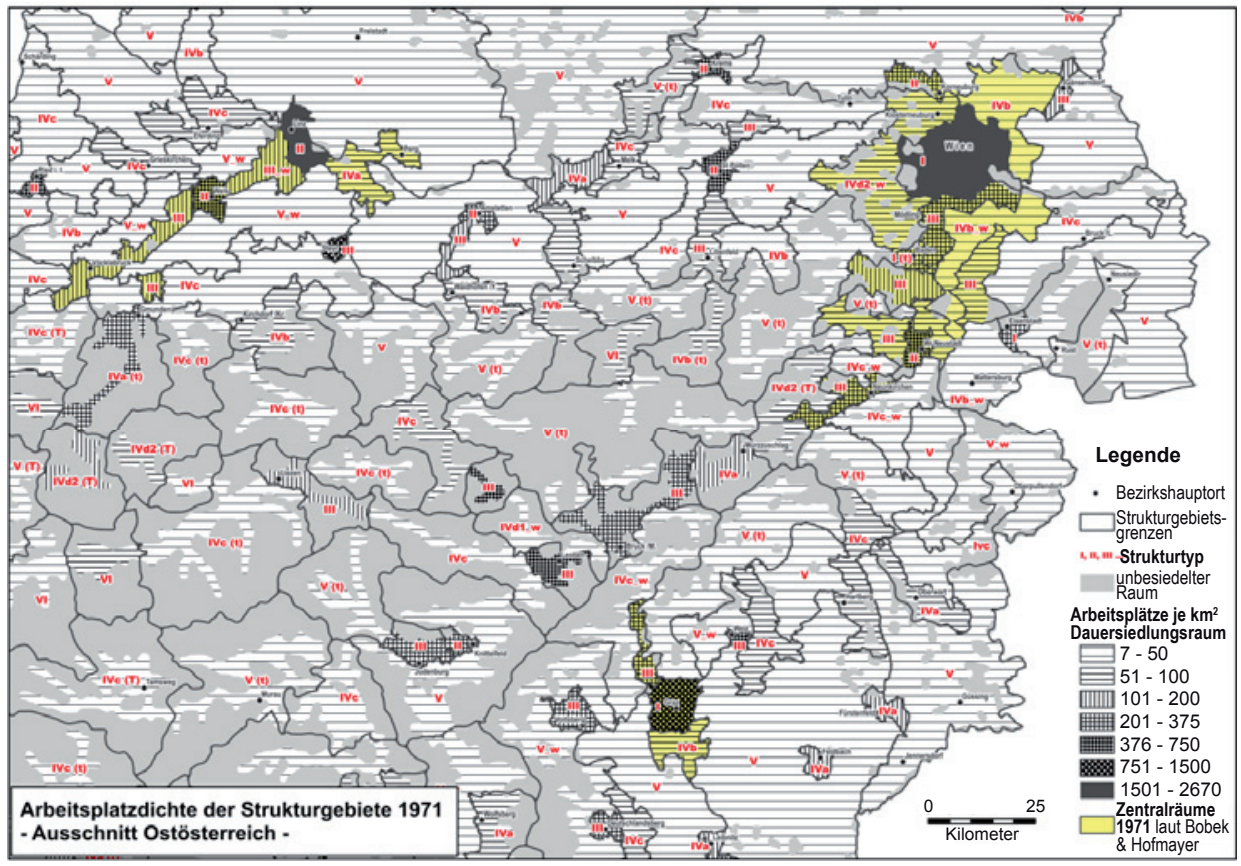

Erläuterung der Strukturtypen I bis VI: siehe Abb. 1. Zusatzzeichen: (t) mit mäßigem Fremdenverkehr Ergänzung: IVd1 Primärsektor $>=15 \%, \quad$ (T) mit starkem Fremdenverkehr IVd2 Primärsektor $<15 \%$. _ _ Wohncharakter (Pendlerbilanzindex <65)

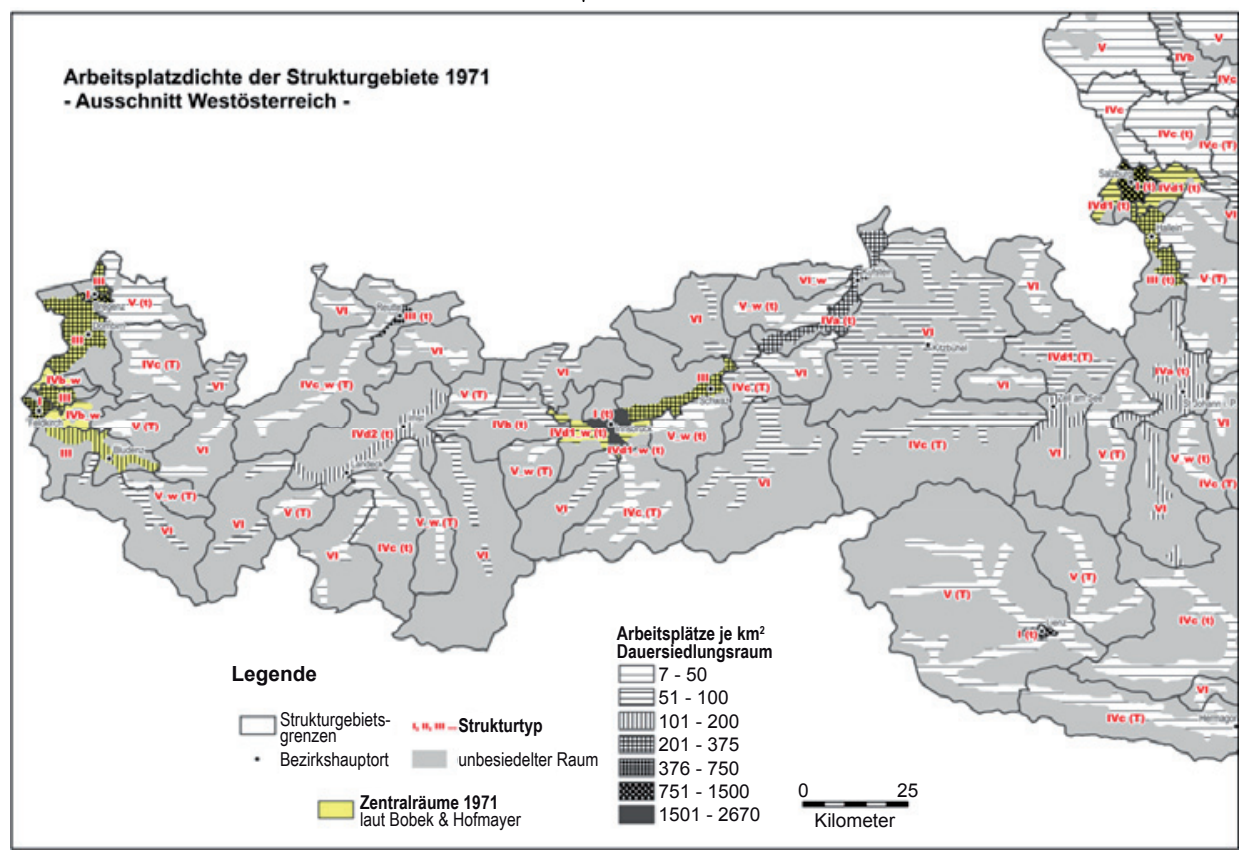

Quellen: Bobek \& Hofmayer (1981, Kap. 4 und Anhang-Karte I); eigene Berechnungen

Abb. 2: Arbeitsplatzdichte der Strukturgebiete und Abgrenzung der Zentralräume 1971 
Die Ausdehnung der wirtschaftsstrukturellen Zentralräume ist in Abbildung 2 durch einen gelben Farbton gekennzeichnet. Am größten war der Zentralraum von Wien, gefolgt von jenem von Linz und dem Vorarlbergs. Rund um die Hauptregionszentren Graz, Salzburg und Innsbruck waren wirtschaftliche Intensivgebiete ebenfalls vorhanden, aber nur kleinflächig ausgeprägt. Angrenzend an Klagenfurt gab es überhaupt kein Gebiet, das als Teil eines wirtschaftsstrukturellen Zentralraums einzustufen gewesen wäre; daher ist Klagenfurt in Abbildung 2 nicht dargestellt.

In Bezug auf die inhaltlich-sektorale Struktur der Zentralräume ist ersichtlich, dass eines der Hauptregionszentren, nämlich Linz, nicht dem dienstleistung sbetonten Typ I, sondern dem Typ II (industriebetont) entsprach. Sekundärzentren, wie im Modell dargestellt, existierten nur in den Hauptregionen Wien (Baden, Wiener Neustadt, Korneuburg - Stockerau) und Linz (Wels); das Gebiet Feldkirch (Typ I) zählt nicht als Sekundärzentrum, sondern als zweites Hauptregionszentrum in Funktionsteilung mit Bregenz.

Räumliche Struktur der Zentralräume: Angrenzend an jedes Hauptregionszentrum erstreckten sich jeweils ein Industriegebiet (Typ III) und zumeist auch - Salzburg und Innsbruck ausgenommen - industrialisierte Menggebiete (Typ IVa oder IVb). Dienstleistungsbetonte Wohngebiete (Typ IVd_w) hatten sich bis 1971 nur in den Zentralräumen von Wien, Salzburg und Innsbruck entwickelt, nicht jedoch in der Linzer, Grazer und Vorarlberger Hauptregion.

In punkto Arbeitsplatzdichte bestand 1971 in allen Hauptregionen Österreichs ein Dichtegradient vom Hauptzentrum nach außen: Die Zentralräume heben sich durch höhere Dichtewerte von der umliegenden Peripherie ab. In einigen alpinen Hauptregionen steigt allerdings die Arbeitsplatzdichte in der Peripherie durch intensiven Tourismus wieder etwas an. Eine Besonderheit der Ostregion war die geringe Arbeitsplatzdichte der Menggebiete des Typs IVb, welche sogar unter jener des Wohngebiets Wienerwald (IVd2_w) lag (vgl. Abb. 2).

\subsection{Aussagen über ubiquitäre Wirtschaftssektoren und deren Beschäftigtenanteile}

Eine weitere, empirisch bemerkenswerte Erkenntnis der BoBEK-HofMAYER'schen Regionalisierung ist der Nachweis, dass zwei der fünf betrachteten Wirtschaftsbereiche, nämlich Gewerbe (ohne Industrie) und Dienstleistungen, in allen Teilräumen Österreichs mit einem gewissen Beschäftigtenanteil vertreten sind. Darin drückt sich eine für die Versorgung der Wohnbevölkerung notwendige Basisausstattung (,Minimum Requirement') aus.

Gewerbe- und Dienstleistungsbeschäftigte zusammen hatten 1971/73, betrachtet man die Daten administrativer Gebiete, in jedem Politischen Bezirk einen Anteil von zumindest 40\% der Arbeitsbevölkerung (vgl. BobeK \& Hofmayer 1981, S. 11). Für die damals abgegrenzten Strukturgebiete ermittelten die Autoren den Beschäftigtenanteil ubiquitärer Sektoren mit genau 30\% der Arbeitsbevölkerung, wobei auf das Gewerbe $14 \%$ und auf Dienstleistungen $16 \%$ (davon Gastgewerbe knapp 2\%, übrige Dienstleistungen $14 \%$ ) entfielen. 


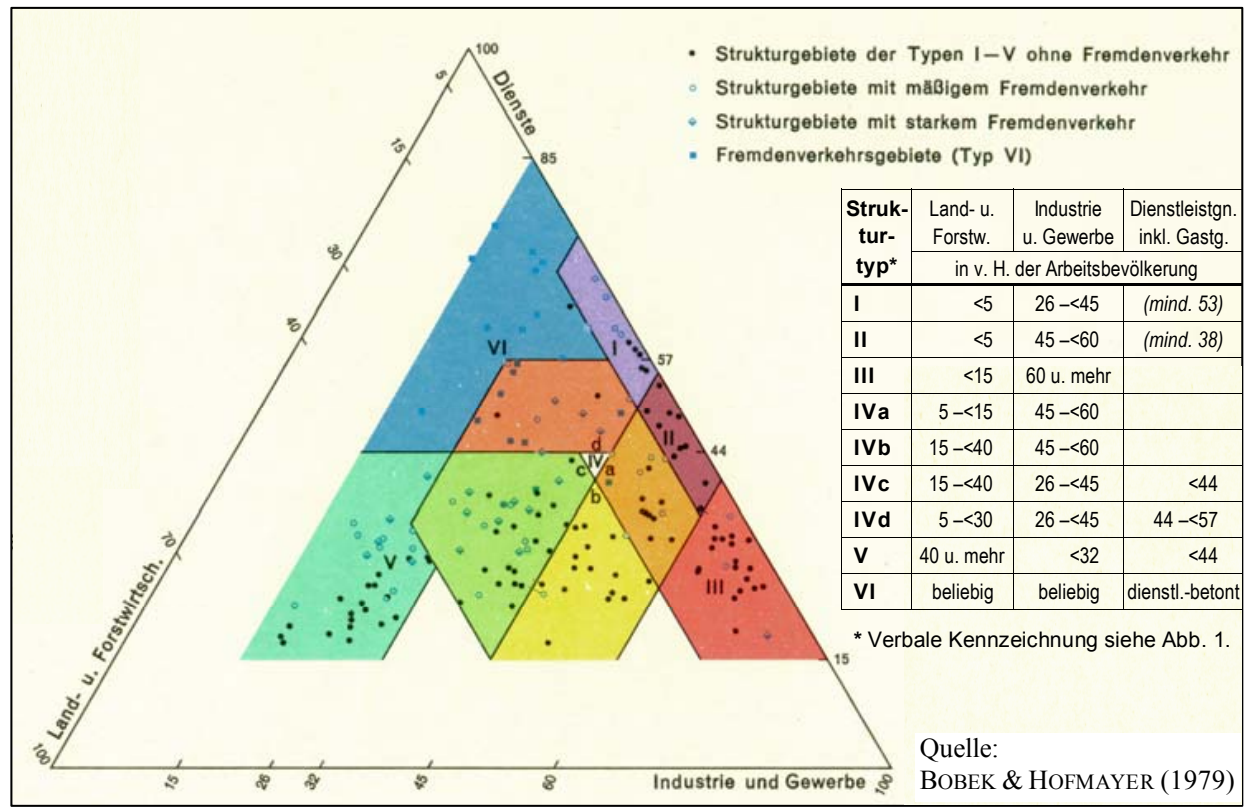

Abb. 3: Dreieckskoordinatendiagramm der Strukturgebiete 1971

Das oben dargestellte Dreieckskoordinatendiagramm (vgl. Abb. 3) zeigt für den Stand 1971/73 sowohl die endgültigen Wertgrenzen der Strukturtypen (Linien parallel zu den Dreieckskanten) als auch die sektoralen Beschäftigtenanteile aller Strukturgebiete (positionierte Punktsignaturen). Am linken und am unteren Rand des Dreiecks sind die Beschäftigtenanteile ubiquitärer Sektoren durch Nicht-Färbung der betreffenden Flächen (je ca. 15\% des Sekundär- bzw. Tertiärsektors) erkennbar.

\section{Die wirtschaftsräumliche Gliederung Österreichs zum Stand 2001}

Im Rahmen dieses Beitrags ist es nicht möglich, die neue Regionalisierung mit allen ihren Ergebnissen vorzustellen. Die folgenden Ausführungen beschränken sich, nach einem Überblick über die summarische Ergebnisse (Abschnitt 3.1), auf zwei Themen:

- kritische Überprüfung der erwähnten theoriebezogenen Aussagen BoBEKs: vgl. Abschnitt 3.2;

- Vergleich der räumlich-sektoralen Struktur ausgewählter österreichischer Wirtschaftsräume 1971/73 und 2001: vgl. Abschnitt 3.3.

Die neue Regionalisierung beruht auf denselben Datengrundlagen wie die frühere: den Gemeindeergebnissen der Volkszählung 2001, der Tourismusstatistik 2001 und der Arbeitsstättenzählung, welche 2001 sogar zeitgleich mit der Volkszählung durchgeführt wurde. Der Gebietsstand ist 2001, d.h. Grenzänderungen seit 1971 wurden nicht rückgängig gemacht. 
Die Methode der Gemeindetypisierung und der Gebietsbildung wurde genau beibehalten. Auch die kartographische Darstellung entspricht weitestgehend der früheren Karte. Sektoralstruktur und Pendlerbilanz sind mit denselben Signaturen wie für 1971 dargestellt. Nur bei der Darstellung der Tourismusintensität wurden zwei Modifikationen vorgenommen:

(a) Es wird die Tourismusintensität jeder Gemeinde individuell dargestellt, bei der früheren Karte war es die durchschnittliche Intensität jedes Gebietes; letztere wird jedoch auch für 2001 in der Gebietsliste ausgewiesen. Damit sind Intensitätsabstufungen innerhalb von Tourismusgebieten und isolierte Tourismusgemeinden in nicht-touristischen Gebieten erkennbar.

b) Die Wertgrenzen der Tourismusintensität wurden geringfügig erhöht: die Wertgrenze zwischen mäßigem und starkem Tourismus von 4.000 auf 5.000 Nächtigungen je 100 Einwohner, und jene zwischen starkem und dominantem Tourismus von 9.000 auf 10.000. Begründet wird dies mit dem Anstieg der Nächtigungen in Österreich zwischen 1971 und 2001.

Für den vorliegenden Beitrag wurde die Regionalisierung nochmals überprüft, und vereinzelt wurden Änderungen in der Gebietsabgrenzung gegenüber der Dissertation (KuLMHOFER 2009) vorgenommen. Dabei erhöhte sich auch die Zahl der abgegrenzten Strukturgebiete (inklusive Teilgebiete) von 241 auf 244.

\section{1 Überblick: Ergebnisse der Gliederung 2001 im Vergleich mit 1971}

Vorangestellt sei ein Überblick über die Strukturgebiete und ihr ökonomisches Gewicht in Österreich 2001 im Vergleich zu 1971 (vgl. Tab. 1 und Abb. 4).

Aus Tabelle 1 ersieht man unter anderem, dass zwei der 1971 festgestellten Strukturtypen - industriell-gewerblich-agrarische Menggebiete (IVb) und Agrargebiete $(V)-2001$ überhaupt nicht mehr vorhanden waren. Andererseits erwies es sich als notwendig, 2001 einen neuen Strukturtyp VII „urbanisierte Dienstleistungsgebiete“ zu definieren, der dieselbe Sektoralstruktur wie die Zentren (Typ I), jedoch keinen Einpendlerüberschuss aufweist (Beispiele: Raum Gänserndorf - Wolkersdorf nordöstlich von Wien, Raum Kalsdorf - Wildon südlich von Graz, Oberes Inntal westlich von Innsbruck). Dessen ungeachtet entfällt mehr als die Hälfte der Beschäftigten 2001 auf Zentren $(58,3 \%)$.

Abbildung 4 stellt die Beschäftigtenstruktur der Strukturgebiete für beide Zeitpunkte dar, wobei Sekundär- und Tertiärsektor weiter untergliedert werden: ersterer in Industrie i.e.S. und übrige Sachgüterproduktion („Gewerbe“; vgl. oben 2.2), letzterer in Gastgewerbe und alle übrigen Dienstleistungen. Außerdem wird für 2001 der so stark überwiegende Strukturtyp I in drei Teilmengen differenziert: Zentren stricto sensu (,Z“), aus welchen Wien nochmals herausgehoben wird, und Zentren des Subtyps „Z(i)“ (Zentren mit gewisser Industrialisierung, definiert durch ein Überwiegen der Industrie über das Gewerbe im Sekundärsektor). Von den 62 Zentren-Strukturgebieten entfallen jeweils genau 31 auf ,Z“ und „Z(i)“. 


\begin{tabular}{|c|c|c|c|c|c|c|c|c|c|}
\hline \multirow{3}{*}{$\begin{array}{l}\text { Strukturtyp } 1971 \\
\text { Kurzbezeichnung } \\
\text { (vgl. Abb. 1) }\end{array}$} & \multirow{3}{*}{$\begin{array}{l}\text { Anz. } \\
\text { Geb. } \\
(*)\end{array}$} & \multicolumn{8}{|c|}{ Arbeitsbevölkerung 1971} \\
\hline & & \multicolumn{2}{|c|}{ insgesamt } & \multicolumn{2}{|c|}{ Primärsektor } & \multicolumn{2}{|c|}{ Sekundärsektor } & \multicolumn{2}{|c|}{ Tertiärsektor } \\
\hline & & absolut & $\%$ & absolut & $\%$ & absolut & $\%$ & absolut & $\%$ \\
\hline $\mathrm{I} Z \mathrm{Ze}$ & 11 & 1.178 .569 & 38,8 & 316 & 2,9 & 470.897 & 36,3 & .356 & 53,1 \\
\hline II industr. Zentr. & 9 & 264.194 & 8,7 & 3.461 & 0,8 & 133.603 & 10,3 & 127.130 & 9,7 \\
\hline III Ind.-g & 29 & 432.070 & 14,2 & 240 & 4,0 & 288.925 & 22,3 & 862 & 9,6 \\
\hline IVa i. & 14 & 1. & 5,0 & 6 & 3,2 & 46 & 6,1 & 58 & 4,5 \\
\hline IVb i.-g. & 17 & 1 & 3,7 & 08 & 5,5 & 400 & 4,3 & 37 & 2,4 \\
\hline IVc a.-g. I & 36 & & 8,0 & 96 & 16,4 & & 4 & 89 & 5,7 \\
\hline IVd/e die. Mengg. & 9 & 56.750 & 1,9 & 6.881 & 1,6 & 21.109 & 1,6 & 28.759 & 2,2 \\
\hline V Agrargebiete & 52 & 505.169 & 16,6 & 266.904 & 61,8 & 122.200 & 9,4 & 116.065 & 8, \\
\hline VI FV-Gebi & 30 & 98.099 & 3,2 & 16.441 & 3,8 & 29.596 & 2,3 & 52.061 & 4, \\
\hline Summe & 207 & 3.039 .693 & 100 & 431.563 & 100 & 1.298 .369 & 100 & 1.309 .717 & 100 \\
\hline
\end{tabular}

\begin{tabular}{|c|c|c|c|c|c|c|c|c|c|}
\hline \multirow{3}{*}{$\begin{array}{l}\text { Strukturtyp } 2001 \\
\text { Kurzbezeichnung } \\
\text { (vgl. Abb. 5) }\end{array}$} & \multirow{3}{*}{$\begin{array}{l}\text { Anz. } \\
\text { Geb. } \\
(*)\end{array}$} & \multicolumn{8}{|c|}{ Arbeitsbevölkerung 2001} \\
\hline & & \multicolumn{2}{|c|}{ insgesamt } & \multicolumn{4}{|c|}{ Primärsektor Sekundärsektor } & \multicolumn{2}{|c|}{ Tertiärsektor } \\
\hline & & absolut & $\%$ & absolut & $\%$ & absolut & $\%$ & absolut & $\%$ \\
\hline I Ze & 62 & 1.994 .189 & 58,3 & 13.567 & 9,4 & 457.408 & 45,5 & 1.523 .214 & 67,1 \\
\hline II in & 20 & 285.574 & 8,4 & 6.374 & 4,4 & 146.000 & 14,5 & 133.200 & 5 , \\
\hline III Ind & 3 & 9.386 & 0,9 & 663 & 0,5 & .480 & 1,9 & 9.243 & 0 , \\
\hline IVa i.-g. Mengg. & 14 & .981 & 4,4 & 12.582 & 8,7 & .119 & 7,4 & 280 & 2 \\
\hline IVb i.-g.-a. N & 0 & & & & & & & & \\
\hline IVc a.-g. Me & 7 & 1.394 & 3,0 & 22.460 & 15,6 & 427 & 3,5 & 507 & 1 , \\
\hline IVd d.-a. N & 30 & 185.837 & 5,4 & 40.283 & 28,0 & 52.009 & 5,2 & 545 & 4,1 \\
\hline IVe d & 53 & 391.179 & 11,4 & 35.688 & 24,8 & 137.719 & 13,7 & 217.772 & 9 , \\
\hline $\mathrm{V} \mathrm{Ag}$ & 0 & & & & & & & & \\
\hline VI Tourismusg. & 38 & 128.449 & 3,8 & 6.871 & 4,8 & 30.547 & 3,0 & 91.031 & 4, \\
\hline VII** urb. Dienst-g. & 17 & 151.862 & 4,4 & 5.501 & 3,8 & 52.383 & 5,2 & 93.978 & 4,1 \\
\hline Summe & 244 & 3.419 .851 & 100 & 143.989 & 100 & 1.005 .092 & 100 & 2.270 .770 & 10 \\
\hline
\end{tabular}

Quelle: Bobeк \& Hofmayer (1981, Anhang-Tabelle „Typenübersicht“); eigene Berechnungen (*) inklusive Teilgebiete; ** neuer Strukturtyp; Erläuterung im Text

Tab. 1: Verteilung der Arbeitsbevölkerung nach Sektoren auf Strukturgebietstypen, 1971 und 2001

Während der Anteil echter Industrie an der AB in Wien und den übrigen Zentren “Z“ nur 8-9\% beträgt, erreicht er in den Zentren des Subtyps „Z(i)“ rund 18\%. In den neuen urbanisierten Dienstleistungsgebieten (Typ VII) beträgt der Anteil etwa $14 \%$.

Weiters ist in Abbildung 4 ersichtlich, dass sich in den meisten Strukturtypen trotz gleichbleibender Schwellenwerte der Dienstleistungsanteil erhöht hat. Dabei haben sich 


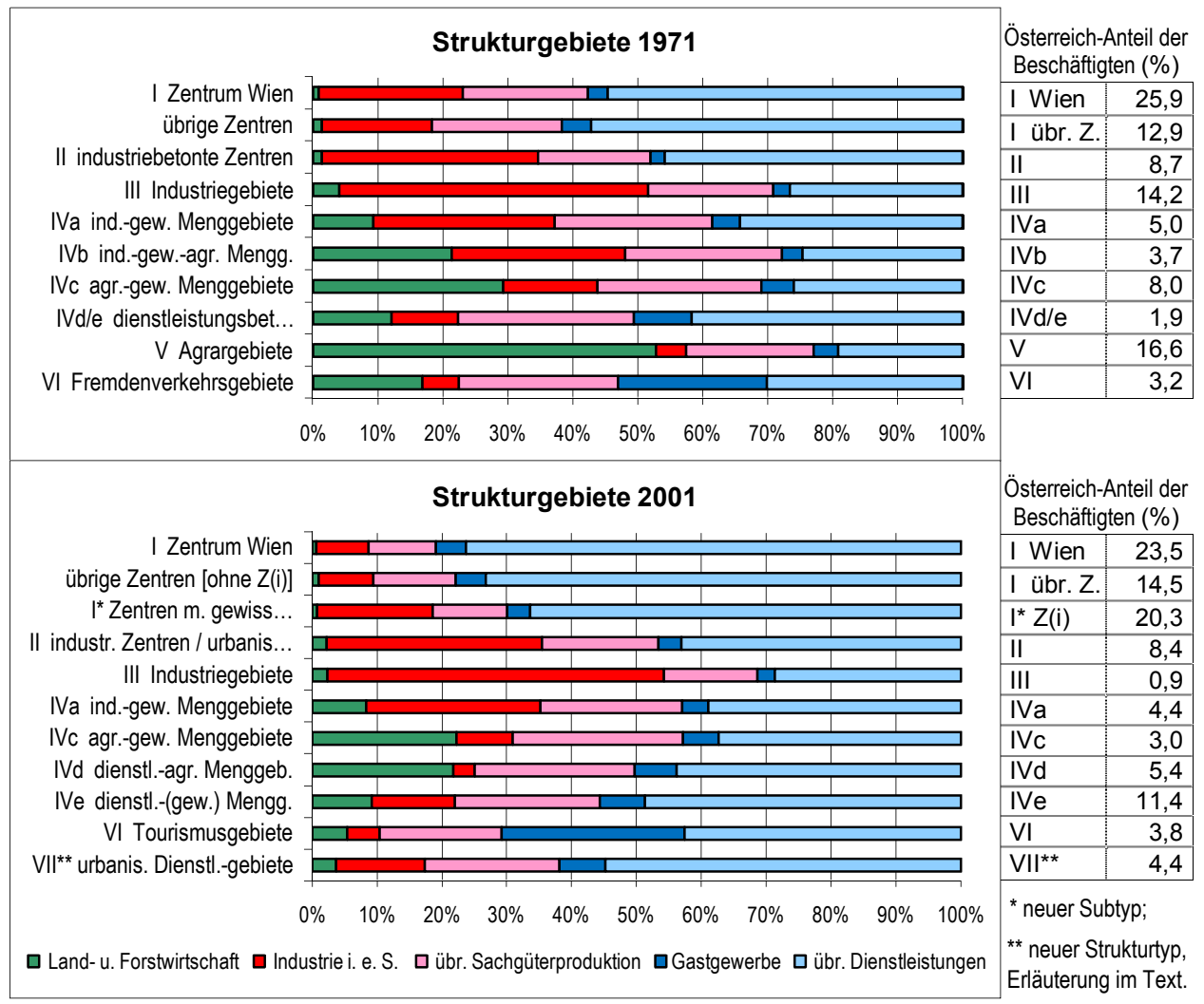

Abb. 4: Beschäftigtenstruktur der Gebietstypen nach Teilsektoren, 1971 und 2001

die Beschäftigtenanteile ubiquitärer Sektoren (vgl. oben 2.4) wesentlich geändert: 2001 entfallen nur noch $8 \%$ auf Gewerbe, das Gastgewerbe blieb mit $2 \%$ gleich, die übrigen Dienstleistungen sind nunmehr mit zumindest $25 \%$ in jedem Strukturgebiet vertreten.

Die gewaltigen Veränderungen im Strukturgebietsgefüge - Abnahme agrarischer und industriebetonter Gebiete bei gleichzeitiger Zunahme dienstleistungsbetonter Gebiete - werden im Folgenden vor dem Hintergrund der referierten Aussagen BoBeKs näher erläutert.

\section{2 Überprüfung der theoriebezogenen Aussagen BовEKs}

\subsubsection{Aktualisierung des wirtschaftsstrukturellen Raummodells}

Aus der neuen wirtschaftsstrukturellen Gliederung lässt sich nachstehendes Raummodell (vgl. Abb. 5) ableiten. Es umfasst nach wie vor die zwei Kategorien Zentralraum und Peripherie. 

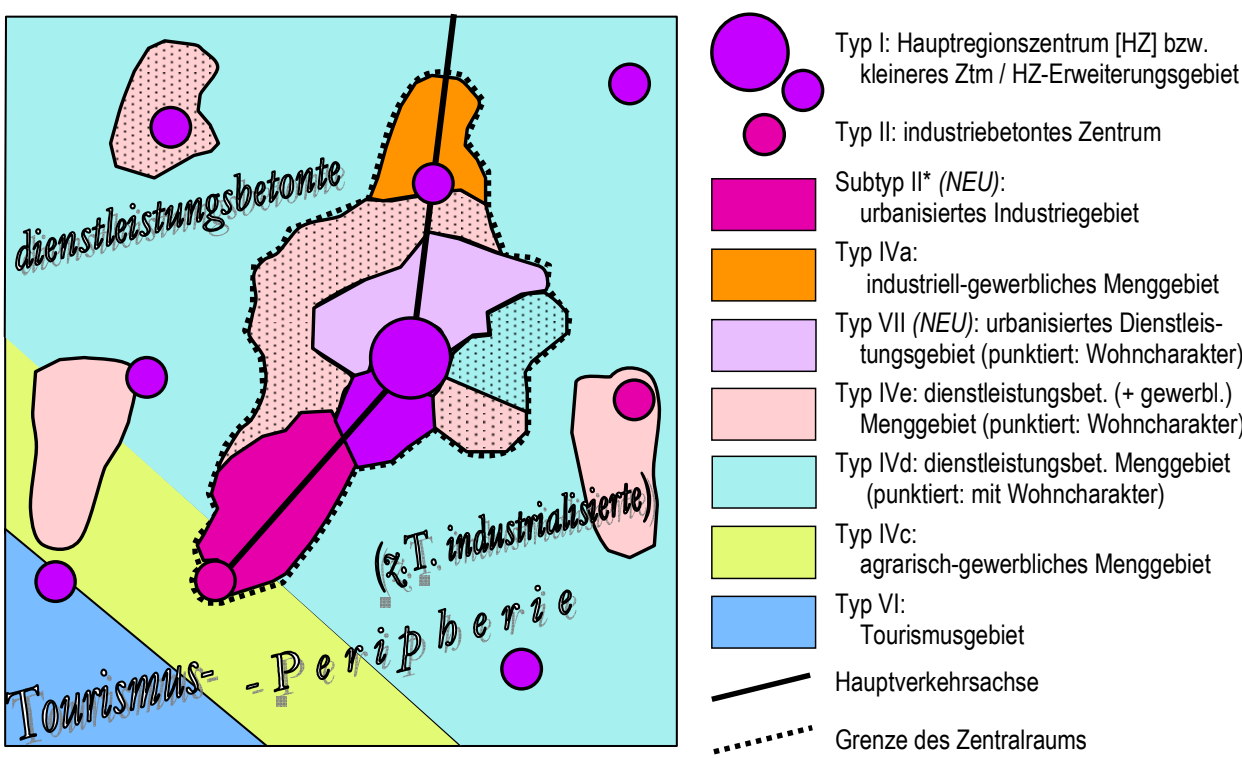

Entwurf: Kulmhofer 2009. Anmerkung: Die sehr vielfältigen Strukturgebiete der Peripherie sind nur auszugsweise dargestellt.

Abb. 5: Das neue Raummodell der Wirtschaftsstruktur Österreichs (Stand 2001)

Die Hauptregionszentren sind dem Typ (I) nach unverändert geblieben, allerdings dominieren nunmehr die Tertiärbeschäftigten noch deutlicher die Struktur.

Übriger Zentralraum: Angrenzend an die Hauptzentren finden sich nach wie vor Gebiete mit intensiver Wirtschaft, die aber nicht mehr industrie-, sondern dienstleistungsbetont sind. Die Struktur der Hauptzentren (Typ I und Einpendlerüberschuss) hat sich auf Umlandgemeinden ausgedehnt, es entstanden Hauptzentrums-Erweiterungsgebiete; sie nehmen zumeist die Stelle früherer Industriegebiete ein. Die Sekundärzentren haben sich gegenüber 1971 vermehrt - sie haben zumeist Typ I, nur selten Typ II -, auch durch Anbindung entfernter Bezirkshauptorte an den sich ausdehnenden Zentralraum. Industrie ist zwar sektoral untergeordnet, doch nach wie vor vertreten in den zwei genannten Gebietstypen sowie in urbanisierten Industriegebieten, die die gleiche Sektoralstruktur wie industrialisierte Sekundärzentren (Typ II), aber Auspendlerüberschuss aufweisen; in einigen Hauptregionen gibt es auch noch industriell-gewerbliche Menggebiete des Typs IVa. Ausgedehnt haben sich die Wohngebiete (Typ IVe_w, in Abb. 2 als IVd2_w bezeichnet). Ein neuer Gebietstyp, häufig am Standort früherer Wohn- oder Industriegebiete, sind die urbanisierten Dienstleistungsgebiete (Typ VII), welche dieselbe Sektoralstruktur wie Typ I, jedoch Auspendlerüberschuss aufweisen.

In der Peripherie Österreichs sind die Agrargebiete völlig verschwunden. Den größten Teil der Fläche nehmen Menggebiete (meist IVe, seltener IVd, IVa und IVc) ein; Menggebiete des Typs IVb sind ebenfalls nicht mehr vorhanden, ebenso Industriegebiete (Typ III) mit Ausnahme eines kleinen Gebiets im Waldviertel, wo aber inzwischen die Industriedominanz auch verloren ging. Dagegen hat sich die Zahl der 
als eigene Strukturgebiete ausgewiesenen Zentren (zumeist Typ I) in der Peripherie vervielfacht; neu hinzu kamen vor allem Bezirkshauptorte, deren Arbeitsplatzzahl auf $>5.000$ zunahm.

Die ganzseitige Abbildung 6 zeigt die im Jahr 2001 vorhandenen Realisierungen des Raummodells in den Hauptregionen Österreichs, mit Kennzeichnung der Zentralräume und der Arbeitsplatzdichte wie in Abbildung 2. Nicht dargestellt ist wiederum der Raum Klagenfurt, wo ein zentrales Intensivgebiet nach wie vor kaum ausgebildet ist; es besteht rund um das Hauptzentrum nur ein dienstleistungsbetontes Wohngebiet (Typ IVe_w).

\section{Ausdehnung und Größe der Zentralräume:}

- In der Hauptregion Wien hat sich der „Intensivraum“ flächenmäßig wenig geändert. Kleinen Einbußen am Ost- und Südrand steht eine größere Ausdehnung auf burgenländisches Gebiet im Raum Mattersburg gegenüber. Damit ist nun auch das Zentrum Eisenstadt räumlich-strukturell an den Zentralraum von Wien angebunden.

- In der Hauptregion Linz hat sich der Zentralraum wesentlich ausgedehnt, sowohl im $\mathrm{N}$ und $\mathrm{O}$ in das untere Mühlviertel als auch im SW im Alpenvorland bis Vorchdorf bzw. bis Gmunden (Sekundärzentrum).

- Rund um Graz hat sich der Zentralraum in alle Richtungen stark vergrößert, vor allem entlang der Südbahnachse und entlang der Südautobahn A2 (von Gleisdorf im O bis Köflach im W), mit Anbindung der neuen Sekundärzentren Leibnitz und Weiz.

- Der Salzburger Zentralraum erstreckt sich nach N über den ganzen Flachgau und nach S entlang der Hauptverkehrsachse bis Bischofshofen; St. Johann im Pongau als angrenzendes neues Zentrum versorgt vor allem periphere Tourismusgebiete und zählt daher nicht mehr zum Zentralraum.

- Der Innsbrucker Zentralraum reicht im Unterinntal so wie 1971 nur bis Jenbach, umfasst aber nun das gesamte Mittelgebirge östlich und westlich von Innsbruck; im Oberinntal hat er sich bis Telfs ausgedehnt.

- Der Zentralraum Vorarlbergs, der schon 1971 das Rheintal und den Walgau ausfüllte, hat sich flächenmäßig kaum verändert.

Inhaltlich-sektorale Struktur der Zentralräume: Die beiden größten Zentralräume Österreichs, Wien und Linz, werden in Abschnitt 3.3 in ihrer Struktur und Entwicklung vergleichend vorgestellt. An dieser Stelle werden daher nur die übrigen Zentralräume kurz charakterisiert. ${ }^{3}$

- Der gegenüber 1971 stark ausgedehnte Grazer Zentralraum umfasst die meisten der im Raummodell enthaltenen Strukturtypen, darunter einen Kranz von Wohngebieten im W, N und NO der Stadt. Im Jahr 2001 war ein Hauptzentrum-Erweiterungsgebiet noch nicht ausgeprägt, aber in Ansätzen am südlichen Stadtrand erkennbar (Gebiet des Typs VII im Übergang zu I, da Pendlerbilanz fast ausgeglichen).

- Im Salzburger Zentralraum besitzt das Hauptzentrum ein strukturell ganz ähnliches kleines Erweiterungsgebiet (Wals-Siezenheim) im W; im N und O ist Salzburg von

\footnotetext{
3) Farbdarstellungen aller Gebiete für 1971 und 2001 und Listen ihrer wirtschaftsstrukturellen Kenndaten finden sich im Anhang (zwei Faltkarten mit Tabellen auf der Rückseite).
} 

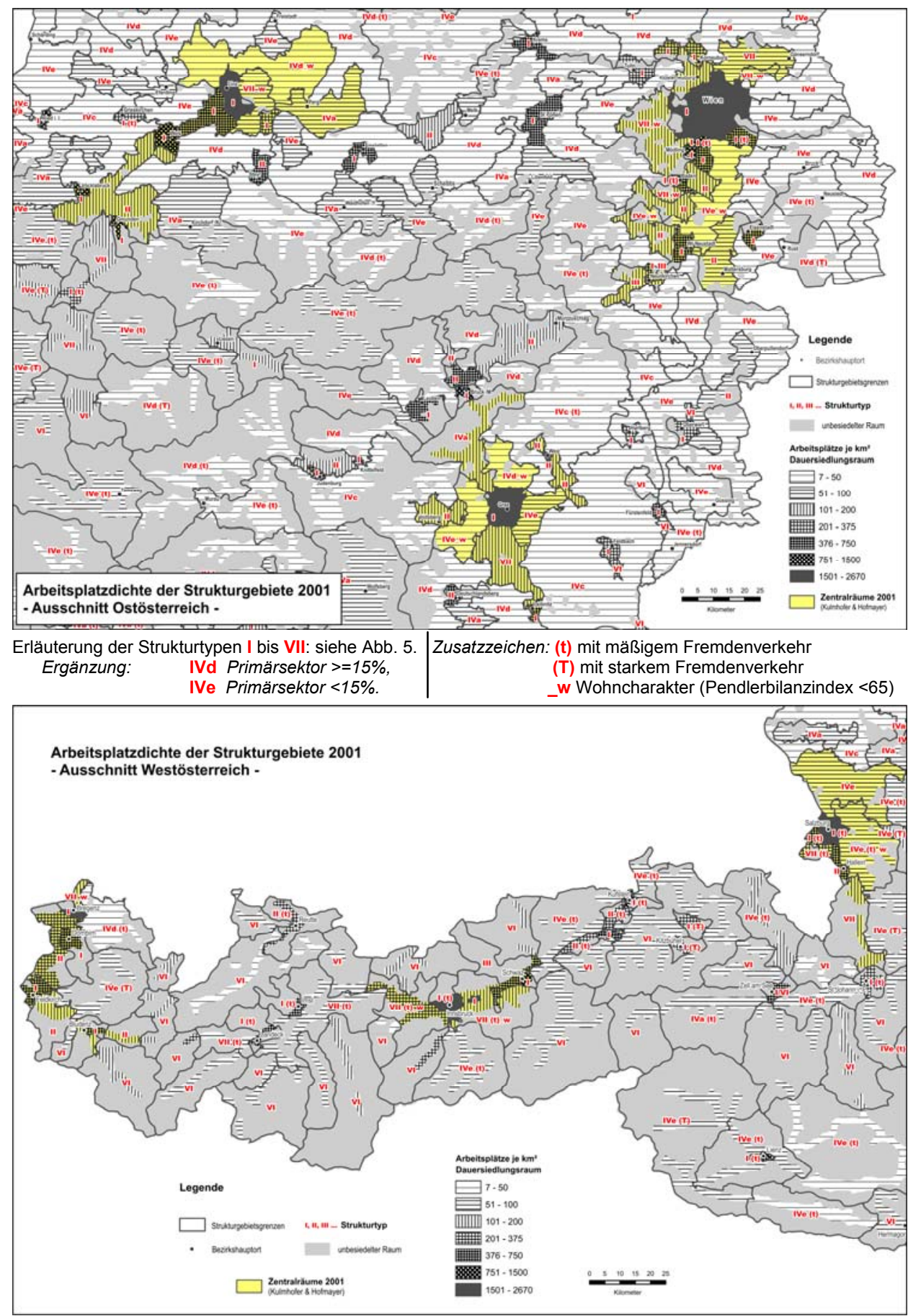

Quelle: Eigene Darstellung unter Verwendung von KULMHOFER 2009

Abb. 6: Arbeitsplatzdichte der Strukturgebiete und Abgrenzung der Zentralräume 2001 
dienstleistungsbetonten Menggebieten (IVe, zum Teil mit Wohncharakter) umgeben. Im $\mathrm{S}$ bildet Hallein ein industriebetontes Sekundärzentrum (Typ II), angrenzend erstrecken sich urbanisierte Dienstleistungsgebiete (VII: Grödig bzw. Salzachtal bis Bischofshofen), jedoch ohne Wohncharakter.

- Der Innsbrucker Zentralraum umfasst neben dem Hauptzentrum das suburbane Zentrum Hall in Tirol (Typ I) und daran anschließend noch ein echtes Industriegebiet (III) von Wattens bis Jenbach. Die Industriedominanz ergibt sich daraus, dass die Bezirksstadt Schwaz, ähnlich wie Neunkirchen im Wiener Raum, nunmehr als Sekundärzentrum ausgegliedert ist; zum Unterschied vom Industriegebiet Schwarzatal weist das Tiroler Industriegebiet jedoch Einpendlerüberschuss auf. Den übrigen Zentralraum Tirols nehmen urbanisierte Wohngebiete (VII_w) ein.

- Auch der Vorarlberger Zentralraum entspricht dem neuen Raummodell. Neben den beiden Hauptzentren Bregenz und Feldkirch (neu abgegrenzt als „Doppelzentrum“ mit Rankweil) heben sich Dornbirn und Bludenz als neue Sekundärzentren (ebenfalls Typ I) heraus. Das übrige Rheintal und der Walgau, früher Industriegebiete, weisen nun zur Gänze den urbanisierten Industrietyp II auf. Ein kleines urbanisiertes Wohngebiet (VII_w) erstreckt sich nördlich von Bregenz am Bodensee entlang.

Arbeitsplatzdichte der Zentralräume: Diese ist ebenso wie 1971 durchgehend höher als in den umliegenden Peripheriegebieten. Relativ niedrige Arbeitsplatzdichten gibt es nur in Dienstleistungsgebieten der Typen IVd und IVe mit ausgeprägtem Wohncharakter. Letztere sind in den meisten Hauptregionen vertreten, nicht jedoch in Tirol und Vorarlberg.

\subsubsection{Aktualisierung der Standorttendenzen der Wirtschaftssektoren}

Die diesbezüglichen Aussagen BobeKs (vgl. oben) waren überwiegend aus der Retrospektive gewonnen. Eine Erklärung der neueren Standorttendenzen muss auch den inzwischen eingetretenen sektoralen Strukturwandel berücksichtigen (vgl. Tab. 2).

Die theoretischen Ansätze zur Erklärung der diesbezüglichen Phänomene - wie Entagrarisierung, Deindustrialisierung, Ausbreitung neuer Dienstleistungen - sind in der Dissertation dargestellt (vgl. Kulmhofer 2009, Kap. 4). An dieser Stelle sollen nur die beobachteten Standorts- bzw. Verlagerungstendenzen der Wirtschaftssektoren im Strukturgebietsgefüge analysiert werden.

Beim Primärsektor, den Bовек schon 1981 als Reliktphänomen bezeichnet hatte, setzte sich die Schrumpfungstendenz in Österreich so wie im übrigen Europa fort. Die gesamtösterreichischen Daten in Tabelle 2 belegen, dass die Land- und Forstwirtschaft in den vergangenen 30 Jahren etwa zwei Drittel sowohl ihrer Beschäftigten als auch ihres Wertschöpfungsanteils verloren hat; bezogen auf den Beschäftigtenanteil war der Rückgang sogar noch stärker. Weit weniger stark war der Rückzug aus der Fläche: auch am Beginn des 21. Jhs. nehmen land- und forstwirtschaftlich genutzte Flächen noch 85\% der Staatsfläche ein (Wert für 2002: 85,4\% inklusive Weingärten und Almen, ohne Gärten), wobei der überwiegende Teil seit einigen Jahren auf Wald entfällt (43,2\% der Staatsfläche: Statistik Austria, Datenbank ISIS, Segment L3P). 


\begin{tabular}{|c|c|c|c|c|}
\hline & $1971^{(3)}$ & 1981 & 1991 & 2001 \\
\hline $\begin{array}{l}\text { Beschäftigte in } 1.000 \\
\text { (1) (Summe) }\end{array}$ & $\begin{array}{r}433 / 1.332 / 1.322 \\
(3.088)\end{array}$ & $\begin{array}{r}289 / 1.353 / 1.670 \\
(3.312)\end{array}$ & $\begin{array}{r}211 / 1.225 / 2.033 \\
(3.459)\end{array}$ & $\begin{array}{r}146 / 1.053 / 2.400 \\
(3.599)\end{array}$ \\
\hline Beschäftigte in $\%$ & $14 / 43,1 / 42,8$ & $8,7 / 40,9 / 50,4$ & $6,1 / 35,3 / 58,6$ & $4,1 / 29,2$ / 66,7 \\
\hline $\begin{array}{l}\text { Bruttowertschöpfung } \\
\text { (2) in Mrd } € \text { (Summe) }\end{array}$ & $\begin{array}{r}3,1 / 18,4 / 27,9 \\
(49,4)\end{array}$ & $\begin{array}{r}3,5 / 25,8 / 43,2 \\
(72,5)\end{array}$ & $\begin{array}{r}4,5 / 41,6 / 83,8 \\
(129,8)\end{array}$ & $\begin{array}{r}4 / 58,1 / 129,9 \\
(192,0)\end{array}$ \\
\hline Bruttowertsch. in \% & $6,2 / 37,2 / 56,6$ & $4,9 / 35,5 / 59,6$ & $3,4 / 32 / 64,5$ & $2,1 / 30,3 / 67,7$ \\
\hline
\end{tabular}

Quelle: Statistik Austria, interaktive Datenbank ISIS, Abfrage August 2010: (1) Segment A9X: Beschäftigte laut Volkszählung (für 1971: Beschäftigte mit unbekannter Wirtschaftsabteilung proportional auf die Sektoren verteilt); ${ }^{(2)}$ Segment Z9F: Aggregate der Volkswirtschaftlichen Gesamtrechnung nach ESVG 1995 in Euro zu laufenden Preisen, Berechnungsstand Juli 2010; (3) Daten der Bruttowertschöpfung für 1976 (frühestes Jahr der Zeitreihe, Werte für 1971 nicht verfügbar)

Tab. 2: Sektoraler Strukturwandel in Österreich 1971 - 1981 - 1991 - 2001, Angaben jeweils für Primär- / Sekundär- / Tertiärsektor

Was die Standorttendenzen betrifft, so ergibt die neue wirtschaftsstrukturelle Regionalisierung, dass im Primärsektor keine eindeutige Konzentration - etwa durch regionale Spezialisierung - stattgefunden hat. Die Entagrarisierung betraf alle Typen von Strukturgebieten etwa gleich stark. Damit erscheint die Aussage Bobeks (1981, S. 78), dass die Landwirtschaft „auch in den besten Lagen“ an Bedeutung verliert, auch für die neuere Entwicklung bestätigt.

Das bereits erwähnte wirtschaftsräumliche Resultat dieses Prozesses ist, dass die eigentlichen Agrargebiete (Typ V), in welchen 1971 noch 16,6\% der gesamten Arbeitsbevölkerung und $62 \%$ der Beschäftigen im Primärsektor tätig gewesen waren, als Strukturtyp im Jahr 2001 nicht mehr vorhanden sind. Mehr als drei Viertel $(77,1 \%)$ der land- und forstwirtschaftlich Beschäftigten sind heute in Menggebieten verschiedenen Typs (gereiht nach abnehmender Absolutzahl: IVd, IVe, IVc, IVa) tätig.

Der Sekundärsektor hat im betrachteten Zeitraum per Saldo in Österreich ebenfalls an Beschäftigten verloren - nach Absolutzahlen etwa 21\%, nach Beschäftigtenanteil 14 Prozentpunkte. Auch die Bruttowertschöpfung des Sektors, die absolut stark anstieg, hat sieben Prozentpunkte der Österreichsumme eingebüßt (vgl. Tab. 2). Die kleinräumige Analyse nach Strukturgebieten liefert allerdings ein sehr differenziertes Bild, sodass man nicht von einer generellen De-Industrialisierung in Österreich sprechen kann.

Von einer Entindustrialisierung Österreichs kann auch deshalb nicht gesprochen werden, weil 1971-2001 im industriell-gewerblichen Sektor im Zuge erheblicher rationalisierungsbedingter Personaleinsparungen das Produktivitätsniveau (Bruttowertschöpfung je Beschäftigtem) - verglichen mit den beiden anderen Wirtschaftssektoren - überproportional angestiegen ist. Infolge dieses Produktivitätsschubes liegt heute Österreich in der Spitzengruppe wettbewerbsstarker Industriestaaten.

Großräumig hat es eine relative Verlagerung der Industrie aus dem Osten in den Westen Österreichs gegeben, welche auf dem ÖROK-Atlas-Blatt „Veränderung der 
regionalen Wirtschaftsstruktur 1971-2001“ (2004) in Karten und Tabellen dokumentiert ist. Dort wird allerdings nicht die Industrie i.e.S., sondern der gesamte Sekundärsektor betrachtet. Die betreffenden Aussagen lauten:

„Der sekundäre Sektor (...) hat 1971 und 1981 (...) österreichweit noch Anteile von über $40 \%$ erreicht, die allerdings in den darauffolgenden Dekaden auf unter 30\% (2001) sanken. Die Zahl der Arbeitsplätze nahm im Zeitraum 1971-2001 um insgesamt etwa $21 \%$ ab. Nur in Tirol (+10\%) und Salzburg (+2\%) ist die Zahl der Industriearbeitsplätze in den vergangenen dreißig Jahren gestiegen, in allen anderen Bundesländern ging die Zahl der Erwerbstätigen in Industrie und Gewerbe zurück. (...) Die höchsten Abnahmen zwischen 1971 und 2001 verzeichneten Wien (-55\%) und Niederösterreich (-20\%), die niedrigsten Oberösterreich (-4\%) und Vorarlberg (-2\%). Nur wenige Regionen wiesen zwischen 1971 und 2001 deutliche (absolute) Zuwächse auf; dazu zählen das Mostviertel, die Oststeiermark, das Inn- und das Mühlviertel sowie das Tiroler Unterland.“ (ÖROK-Atlas Blatt 02.03.07/2004, Teilblatt „Arbeitsplätze nach Sektoren“)

Bezogen auf die Einbettung der Sachgüterproduktion - Sekundärsektor insgesamt und Industrie i.e.S. - in die räumliche Sektoralstruktur liefert die neue Regionalisierung folgende Ergebnisse (vgl. Tab. 3):

\begin{tabular}{|l|c|c|c|c|}
\hline \multirow{2}{*}{ Strukturtypen } & \multicolumn{2}{|c|}{$1971 / 73$} & \multicolumn{2}{c|}{2001} \\
\cline { 2 - 5 } & $\begin{array}{c}\text { Sek.- } \\
\text { sektor* }\end{array}$ & $\begin{array}{c}\text { Indus- } \\
\text { trie** }\end{array}$ & $\begin{array}{c}\text { Sek.- } \\
\text { sektor* }\end{array}$ & $\begin{array}{c}\text { Indus- } \\
\text { trie** }\end{array}$ \\
\hline I: dienstleistungsbetontes Zentrum & 36,3 & 33,1 & 45,5 & 48,3 \\
\hline II: industriebetontes Zentrum ${ }^{4)}$ & 10,3 & 12,9 & 14,5 & 20,2 \\
\hline III: Industriegebiet & 22,3 & 32,6 & 1,9 & 3,3 \\
\hline IVa: industriell-gewerbl. Menggebiet & 6,1 & 6,5 & 7,4 & 8,7 \\
\hline IVb: industr.-gewerbl.-agrar. Menggebiet & 4,3 & 4,7 & --- & --- \\
\hline IVc: agrarisch-gewerbliches Menggebiet & 7,4 & 5,3 & 3,5 & 1,9 \\
\hline IVd: dienstleistungsbet.-agrar. Mengg. (Wohngeb.) & 1,6 & 0,8 & 5,2 & 1,3 \\
\hline IVe: dienstleistungsbetont (-gewerbl.) Menggebiet & & 13,7 & 10,7 \\
\hline V Agrargebiet & 9,4 & 3,2 & --- & --- \\
\hline VI Fremdenverkehrsgebiet & 2,3 & 0,8 & 3,0 & 1,3 \\
\hline VII urbanisiertes Dienstleistungsgebiet & --- & -- & 5,2 & 4,3 \\
\hline Beschäftigtensumme (=100\%) & $1,298.286$ & 675.086 & $1,005.092$ & 468.508 \\
\hline
\end{tabular}

Quellen: BobeK \& HOFMAYer (1981, S. 72), KuLMHOFER (2009, S. 148); ergänzende Berechnungen.

*) Sekundärsektor laut Volkszählung 1971 bzw. 2001; **) Industrie laut Arbeitsstättenzählung 1973 bzw. 2001

Tab. 3: Verteilung der Sekundärsektor- und Industrie-Beschäftigten auf Strukturgebietstypen 1971/73 und 2001

\footnotetext{
4) Typ II war 1971/73 nur in Form von ,,industriebetonten Zentren“, d.h. in Gebieten mit deutlichem Einpendlerüberschuss vertreten. 2001 ist dieselbe Beschäftigtenstruktur auch in Gebieten mit Auspendlerüberschuss anzutreffen, welche als neuer Subtyp „urbanisierte Industriegebiete“ (II*) bezeichnet werden.
} 
Die eigentlichen Industriegebiete (Typ III, Definition vgl. Abb. 1 und 3), die 1971/73 noch sehr zahlreich und in jeder Hauptregion - wie erwähnt in fast jedem Zentralraum und in vielen Teilen der Peripherie - vorkamen, sind 30 Jahre später bis auf drei Gebiete verschwunden. Dieser Strukturtyp beherbergte damals 33\% der Industriebeschäftigten Österreichs, also etwa gleich viele wie die Zentren (je ca. 220.000); 2001 sind es nur noch 3\% (absolut ca. 15.000).

Das Gros der Industriebeschäftigten arbeitet nunmehr in den Zentren (Typ I und II) sowie in Gebieten der neuen Typen IVe und VII, also in dienstleistungsbetonten Strukturen. Die Absolutzahl der Industriebeschäftigten, die in solchen Strukturen arbeiten, hat sogar zugenommen, allerdings handelt es sich dabei fast durchwegs um Standorte, die früher industriebetonte Struktur aufwiesen. Stattgefunden hat also ganz überwiegend nicht eine Verlagerung der Industrie, sondern eine strukturelle Transformation der Arbeitsplätze im Zuge der Tertiärisierung der Wirtschaft.

Die nachstehende Tabelle 4 zeigt die Veränderung der Lokalisierung der eigentlichen Industrie nach den Kategorien des wirtschaftsstrukturellen Raummodells (vgl.oben, 2.3.2).

Daraus lassen sich folgende drei Aussagen über die Standorttendenzen des Industriesektors im Zeitraum 1971/73 bis 2001 ableiten:

- In allen Hauptregionszentren ging die Zahl der Industriebeschäftigten deutlich zurück, insgesamt um mehr als die Hälfte $(267.000 \rightarrow 129.000)$. Am geringsten war der Rückgang in Bregenz und Graz (20 bzw. 24\%), am stärksten in Wien und Innsbruck (61 bzw. 55\%); in den übrigen alten Landeshauptstädten betrug die Abnahme 40 bis $43 \%$. Da außerdem die Arbeitsbevölkerung durchwegs zunahm, ist eine generell starke De-Industrialisierung der Hauptregionszentren festzustellen. Dieser Prozess wird vor allem in den Kernstadtbereichen der Hauptregionszentren infolge der starken Konkurrenzierung der Industrie und des Gewerbes durch profitablere Nutzungen (Büros, Handelsbetriebe, Wohnbauten) beschleunigt (Phänomen der Opportunitätskosten).

- Die an die Hauptregionszentren angrenzenden Strukturgebiete des übrigen Zentralraums verzeichneten hingegen eine unterschiedliche Industrieentwicklung. In Summe blieb die Zahl der Industriebeschäftigten in diesen „Ergänzungsräumen“ der Hauptregionszentren in Österreich fast unverändert $(161.000 \rightarrow 152.000)$, wobei allerdings die teils beträchtliche Vergrößerung der Zentralräume zu berücksichtigen ist (vgl. Abb. 2 mit Abb. 5). Es ist jedoch eine deutliche Entwicklungsdiskrepanz festzustellen: In den altindustrialisierten Zentralräumen von Wien und Vorarlberg hat die Industriebeschäftigung in dieser Gebietskategorie absolut abgenommen, in den übrigen Hauptregionen hingegen zugenommen. Die absoluten Zunahmen der Industriebeschäftigten sind in zwei Hauptregionen sogar größer als die absoluten Abnahmen im Regionszentrum: In der Steiermark und in Salzburg gab es daher Absolut-Zunahmen der Industrie im Zentralraum (inklusive Hauptregionszentrum), allerdings nur dank der Einbeziehung ehemals peripherer Gebiete in den strukturellen Zentralraum. Relativ gesehen - und dies erscheint in raumstruktureller Hinsicht angesichts der sektoralen Transformation am bedeutsamsten - hat der Anteil der Industrie, der im übrigen Zentralraum lokalisiert ist, in allen Hauptregionen, auch in der Ostregion und in Vorarlberg, zugenommen. 


\begin{tabular}{|c|c|c|c|c|c|}
\hline Hauptregion (HR) & 1973 & & 2001 & & Veränderung \\
\hline Raummodell-Kategorie & $\begin{array}{c}\text { Ind.-besch. } \\
\text { absolut }\end{array}$ & $\begin{array}{l}\% \text { der } \\
\text { HR- } \Sigma\end{array}$ & $\begin{array}{c}\text { Ind.-besch. } \\
\text { absolut }\end{array}$ & $\begin{array}{l}\text { \% der } \\
\text { HR- } \sum\end{array}$ & $\begin{array}{l} \pm \text { Industrie- } \\
\text { beschäftigte }\end{array}$ \\
\hline $\begin{array}{l}\text { Wien (Ostregion) } \\
\text { Hauptregionszentrum } \\
\text { übriger Zentralraum } \\
\text { Peripherie insg. }\end{array}$ & $\begin{array}{r}160.052 \\
66.314 \\
68.519 \\
\end{array}$ & $\begin{array}{l}54,3 \\
22,5 \\
23,2 \\
\end{array}$ & $\begin{array}{l}62.194 \\
38.697 \\
48.858 \\
\end{array}$ & $\begin{array}{l}41,5 \\
25,8 \\
32,6\end{array}$ & $\begin{array}{l}-61,1 \% \\
-41,6 \% \\
-28,7 \% \\
\end{array}$ \\
\hline Hauptregion gesamt & 294.885 & 100,0 & 149.749 & 100,0 & $-49,2 \%$ \\
\hline $\begin{array}{l}\text { Linz } \\
\text { Hauptregionszentrum } \\
\text { übriger Zentralraum } \\
\text { Peripherie insg. } \\
\end{array}$ & $\begin{array}{l}49.600 \\
39.719 \\
52.470\end{array}$ & $\begin{array}{l}35,0 \\
28,0 \\
37,0\end{array}$ & $\begin{array}{l}28.238 \\
40.515 \\
49.255\end{array}$ & $\begin{array}{l}23,9 \\
34,3 \\
41,7 \\
\end{array}$ & $\begin{array}{l}43,1 \% \\
+2,0 \% \\
-6,1 \%\end{array}$ \\
\hline Hauptregion gesamt & 141.789 & 100,0 & 118.008 & 100,0 & $-16,8 \%$ \\
\hline $\begin{array}{l}\text { Graz } \\
\text { Hauptregionszentrum } \\
\text { übriger Zentralraum } \\
\text { Peripherie insg. }\end{array}$ & $\begin{array}{r}27.691 \\
5.372 \\
75.945 \\
\end{array}$ & $\begin{array}{r}25,4 \\
4,9 \\
69,7 \\
\end{array}$ & $\begin{array}{l}20.937 \\
21.498 \\
42.882 \\
\end{array}$ & $\begin{array}{l}24,5 \\
25,2 \\
50,3\end{array}$ & $\begin{array}{r}24,4 \% \\
+300,2 \% \\
-43,5 \% \\
\end{array}$ \\
\hline Hauptregion gesamt & 109.008 & 100,0 & 85.317 & 100,0 & $-21,7 \%$ \\
\hline $\begin{array}{l}\text { Klagenfurt } \\
\text { Hauptregionszentrum } \\
\text { übriger Zentralraum } \\
\text { Peripherie insg. }\end{array}$ & $\begin{array}{r}8.946 \\
0 \\
25.708 \\
\end{array}$ & $\begin{array}{r}25,8 \\
0,0 \\
74,2 \\
\end{array}$ & $\begin{array}{r}5.387 \\
110 \\
22.452 \\
\end{array}$ & $\begin{array}{r}19,3 \\
0,4 \\
80,3\end{array}$ & $\begin{array}{r}-39,8 \% \\
--- \\
-12,7 \% \\
\end{array}$ \\
\hline Hauptregion gesamt & 34.654 & 100,0 & 27.949 & 100,0 & $-19,3 \%$ \\
\hline $\begin{array}{l}\text { Salzburg } \\
\text { Hauptregionszentrum }(*) \\
\text { übriger Zentralraum } \\
\text { Peripherie insg. }\end{array}$ & $\begin{array}{l}9.830 \\
7.571 \\
8.076 \\
\end{array}$ & $\begin{array}{l}38,6 \\
29,7 \\
31,7 \\
\end{array}$ & $\begin{array}{r}5.867 \\
12.176 \\
5.793 \\
\end{array}$ & $\begin{array}{l}24,6 \\
51,1 \\
24,3\end{array}$ & $\begin{array}{r}-40,3 \% \\
+60,8 \% \\
-28,3 \% \\
\end{array}$ \\
\hline Hauptregion gesamt & 25.477 & 100,0 & 23.836 & 100,0 & $-6,4 \%$ \\
\hline $\begin{array}{l}\text { Innsbruck } \\
\text { Hauptregionszentrum } \\
\text { übriger Zentralraum } \\
\text { Peripherie insg. } \\
\end{array}$ & $\begin{array}{r}6.618 \\
11.213 \\
14.810 \\
\end{array}$ & $\begin{array}{l}20,3 \\
34,4 \\
45,4 \\
\end{array}$ & $\begin{array}{r}2.948 \\
14.056 \\
17.487 \\
\end{array}$ & $\begin{array}{r}8,5 \\
40,8 \\
50,7 \\
\end{array}$ & $\begin{array}{l}-55,5 \% \\
+25,4 \% \\
+18,1 \% \\
\end{array}$ \\
\hline Hauptregion gesamt & 32.641 & 100,0 & 34.491 & 100,0 & $+5,7 \%$ \\
\hline $\begin{array}{l}\text { Vorarlberg } \\
\text { Hauptregionszentrum (*) } \\
\text { übriger Zentralraum } \\
\text { Peripherie insg. }\end{array}$ & $\begin{array}{r}4.660 \\
30.657 \\
1.315\end{array}$ & $\begin{array}{r}12,7 \\
83,7 \\
3,6 \\
\end{array}$ & $\begin{array}{r}3.732 \\
24.674 \\
752\end{array}$ & $\begin{array}{r}12,8 \\
84,6 \\
2,6 \\
\end{array}$ & $\begin{array}{l}-19,9 \% \\
-19,5 \% \\
-42,8 \% \\
\end{array}$ \\
\hline Hauptregion gesamt & 36.632 & 100,0 & 29.158 & 100,0 & $-20,4 \%$ \\
\hline Österreich (A) insgesamt & $\begin{array}{c}\text { Ind.-besch. } \\
1973 \\
\end{array}$ & $\begin{array}{c}\% \text { der } \\
\text { A- } \Sigma\end{array}$ & $\begin{array}{c}\text { Ind.-besch. } \\
2001 \\
\end{array}$ & $\begin{array}{c}\% \text { der } \\
\mathrm{A}-\Sigma\end{array}$ & $\begin{array}{l} \pm \text { Ind.-besch. } \\
\text { abs. 1973-2001 }\end{array}$ \\
\hline $\begin{array}{l}7 \text { Hauptregionszentren } \\
\text { übrige Zentralräume }\end{array}$ & $\begin{array}{l}267.397 \\
160.846 \\
\end{array}$ & $\begin{array}{l}39,6 \\
23,8 \\
\end{array}$ & $\begin{array}{l}129.303 \\
151.726 \\
\end{array}$ & $\begin{array}{l}27,6 \\
32,4 \\
\end{array}$ & $\begin{array}{r}-51,6 \% \\
-5,7 \% \\
\end{array}$ \\
\hline Zentralräume insg. & 428.243 & 63,4 & 281.029 & 60,0 & $-34,4 \%$ \\
\hline Peripherie insg. & 246.843 & 36,6 & 187.479 & 40,0 & $-24,0 \%$ \\
\hline Österreich-Summe & 675.086 & 100,0 & 468.508 & 100,0 & $-30,6 \%$ \\
\hline
\end{tabular}

Quellen: Bobek \& Hofmayer (1981, S. 90f.), Kulmhofer (2009, Kap. 12.1); ergänzende Berechnungen. (*) nicht Strukturgebiet, sondern nur Gemeinde Salzburg bzw. Bregenz (zwecks Vergleichbarkeit mit übrigen Hauptregionen)

Tab. 4: Verteilung der Industriebeschäftigten in den Hauptregionen Österreichs auf Raummodell-Kategorien, 1973 und 2001 
- In der Peripherie entwickelte sich die Industrie je nach Hauptregion sehr unterschiedlich. Österreichweit betrug die absolute Abnahme 24\%, relativ gab es eine geringfügige Zunahme um 3 Prozentpunkte, sodass nunmehr $40 \%$ der Industriebeschäftigten in wirtschaftsstrukturell peripheren Räumen arbeiten (nach der Sektoralstruktur überwiegend in dienstleistungsbetonten Gebieten des Typs II, vgl. Tab. 3). Die relative Anteils-Abnahme in der steirischen und salzburgischen Peripherie ist auf die erwähnte Ausdehnung der Zentralräume zurückzuführen. Eine absolute Zunahme der Industriebeschäftigten gab es nur in der Peripherie von Tirol $(+18 \%)$, eine weit unterdurchschnittliche absolute Abnahme in Oberösterreich (-6\%).

Fazit: Die Industrie in der Peripherie konnte sich in Westösterreich sogar absolut halten, im übrigen Österreich, vor allem in der Ostregion, hat sie etwa im Ausmaß des gesamtösterreichischen Durchschnitts verloren.

Insgesamt kann man also im industriell-gewerblichen Sektor eine zentrifugale Standortendenz konstatieren, weg von den größeren Zentren und hin zu den diesen Zentren benachbarten bzw. in ,mittlerer“ geographischer Position und teilweise sogar in peripheren Zonen befindlichen Standorträumen.

Der Tertiärsektor hat im Zuge der allgemeinen Strukturentwicklung absolut und relativ stark zugenommen. Die Zunahme erfolgte im betrachteten Zeitraum kontinuierlich und betraf alle Teilräume Österreichs, wie das folgende Zitat erläutert:

„Die stärkste Ausweitung (ein Plus von mehr als 80\%) erfolgte im Beobachtungszeitraum im Bereich der Dienstleistungen. 1971 wurde für den tertiären Sektor noch ein Anteil von 44,2\% ausgewiesen, 2001 waren es bereits 68,0\%. Diese Entwicklung vollzog sich in allen Regionen und Bundesländern und in allen Dekaden. Die höchsten Zunahmen verzeichneten dabei Vorarlberg, das Burgenland, Niederösterreich und Salzburg. Die hohen (absoluten) Zunahmen konzentrieren sich auf das Umland der großen Städte, auf das Gebiet zwischen Wien und Linz bzw. Linz und Salzburg sowie die Süd- und Oststeiermark, aber auch auf das Nordburgenland. Im Südburgenland, im Wald- und Weinviertel sowie in der östlichen Obersteiermark konnten die Beschäftigungsgewinne im Dienstleistungssektor die hohen Verluste des primären und sekundären Sektors nicht auffangen (...) “(ÖROK-Atlas Blatt 02.03.07/2004, Teilblatt „Arbeitsplätze nach Sektoren“).

Was die Verteilung auf Strukturgebietstypen betrifft, so ist die starke Zunahme der Zahl eigentlicher „Zentren“ die auffälligste Entwicklung überhaupt (vgl. Tab. 1): Die Zentren beherbergen 2001 nicht nur 58\% der Arbeitsbevölkerung und 67\% der Tertiärbeschäftigten Österreichs, sondern auch den Löwenanteil der Industriebeschäftigen (48\%, vgl. Tab. 3). Die große Zahl und das Gewicht der Zentren macht eine Differenzierung in Subtypen sinnvoll, wie sie bereits in Abschnitt 3.1 (vgl. Abb. 4) versucht wurde. Die dort ausgewiesenen Subtypen Z und Z(i) sind allerdings nur nach der Industriebedeutung differenziert. 
Spezifische Differenzierungen innerhalb des Dienstleistungssektors wurden in der Dissertation (Kulmhofer 2009) in mehrfacher Hinsicht vorgenommen. In diesem Beitrag wird nur die funktionelle Differenzierung in produktionsnahe und übrige Dienstleistungen verwendet, anhand derer die wirtschaftsstrukturellen Unterschiede zwischen Zentralen Orten einerseits und neu entstandenen Dienstleistungszentren andererseits besonders deutlich werden.

Die Branchenstruktur des Tertiärsektors dieser neuen suburbanen Zentren(gebiete) unterscheidet sich signifikant von jener der klassischen Versorgungszentren (Hauptregionszentren und übrige Zentren, d.h. aller Viertels- und vieler Bezirkshauptstädte), wie die folgende Tabelle zeigt (vgl. Tab. 5). In allen ,alten“ Zentren, auch in Wien, überwogen auch 2001 noch deutlich die ,gebundenen“ Dienstleistungen, welche primär der Versorgung der Bevölkerung des näheren Umlandes dienen. (Zu Begriff und Bedeutung gebundener und ungebundener Dienstleistungen vgl. MAYERHOFER 1999.)

Die neuen suburbanen Zentren sind die einzige Gebietskategorie, in der mehr als die Hälfte der Tertiärbeschäftigten in produktionsnahen Dienstleistungen (PDL), also überwiegend in ,ungebundenen“ Dienstleistungen, tätig sind. Zu diesen zählen vor allem Großhandel und Lagerung, Spedition und Logistikdienste, Rechts-, Wirtschafts- und technische Dienste. (Zur Abgrenzung vgl. Birner, Schremmer \& TödtLing 1997, S. 28.)

Die neuen suburbanen Zentren bzw. Zentrengebiete weisen darüber hinaus die stärkste Beschäftigtendynamik aller Teilräume Österreichs auf. Die betreffenden Gemeinden waren 1971 noch überwiegend industriell strukturiert (Tertiärsektor nur 32\% der AB); bis 2001 erhöhte sich ihre Arbeitsbevölkerung insgesamt auf das Zweieinhalbfache, die Beschäftigten im Tertiärsektor vermehrten sich auf fast das Fünffache, jene in den produktionsnahen Dienstleistungen (PDL) auf mehr als das Siebenfache (vgl. Tab. 5). Es fand in diesen suburbanen Zonen somit eine deutliche Transformation $\mathrm{zu}$ - vor allem flächenbeanspruchenden - Dienstleistungsaktivitäten statt.

\subsection{Entwicklung der räumlich-sektoralen Struktur ausgewählter Wirtschaftsräume 1971-2001}

In diesem Abschnitt werden die raum- und wirtschaftsstrukturellen Veränderungen anhand ausgewählter Beispiele erläutert, wobei in einer Kombination von Längs- und Querschnittsanalyse jeweils zwei Beispielsräume vorgestellt werden: zwei Zentralräume (3.3.1), zwei ehemalige Agrarräume (3.3.2) und zwei Fremdenverkehrsräume (3.3.3).

Bei den folgenden Kartenvergleichen kommt die dimensionale Beschränkung jeder thematischen Information zum Tragen (vgl. das „M-F-C“-Schema von SinToN 1978): Von den drei Dimensionen Attribut, Zeit und Raum kann nur eine gemessen [M] easured - werden (hier: das Attribut, also die Wirtschaftsstruktur), während eine zweite invariant - [F]ixed - gehalten werden muss (hier: die beiden Zeitpunkte) und die dritte nur als Referenzhintergrund - [C]ontrolled - dienen kann (hier: der Raum, die Bezugsfläche). Weil sich sowohl die Struktur als auch die Ausdehnung der Gebiete in den meisten Fällen geändert hat, ist ein intertemporaler Vergleich nur kartographischvisuell, nicht anhand statistischer Daten möglich. 


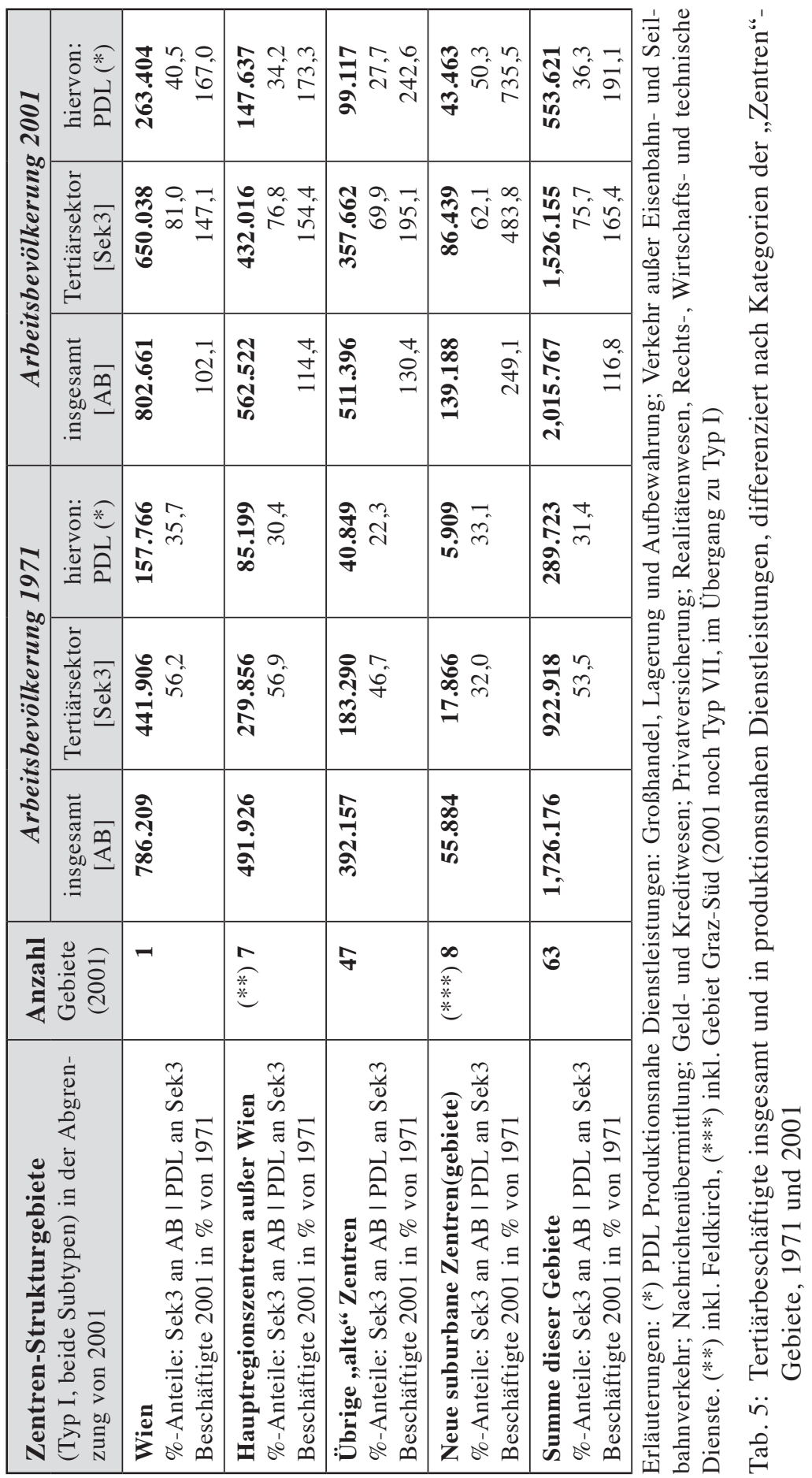




\subsubsection{Beispiele zur Entwicklung der Zentralräume: Vergleich Wien - Linz}

Der Wiener Zentralraum zeigt paradigmatisch die erwähnten Entwicklungen und daher auch die wesentlichen Elemente des neuen Raummodells (vgl. Abb. 7, zur Abgrenzung aller Zentralräume vgl. Abb. 2 und 6).

Gleich geblieben ist der Strukturtyp nur in Wien (Nr. 1, AB 2001802.000 nach 786.000 1971) und im Sekundärzentrum Baden (Nr. 3, Anstieg der AB von 10.000 auf 11.500).

Die früheren Industriegebiete am südlichen Rand Wiens (Schwechat, Vösendorf, Brunn am Gebirge, Mödling-Wiener Neudorf und Umgebung) haben 2001 durchwegs den gleichen Strukturtyp wie Wien (Gebiete Nr. 7, 6, 5, 4 und 8) (5) $^{\text {) }}$ und bilden ein Hauptzentrums-Erweiterungsgebiet mit zusammen ca. 56.000 Arbeitsplätzen, davon ca. 8.500 in der Industrie. Die weiter entfernt liegenden früheren Industriegebiete Traiskirchen, Triestingtal und Piestingtal sind nunmehr urbanisierte Industriegebiete (Typ II, Gebiete Nr. 9, 10, 11); lediglich im Schwarzatal (Nr. 18) - ohne Einschluss von Neunkirchen (Nr. 19), das ein neues, fast industriefreies Sekundärzentrum darstellt - ist die Industrie noch dominant (Typ III). Östlich des großen Sekundärzentrums Wiener Neustadt (Nr. 12, Typ I, früher Typ II) hat sich der zentrale Intensivraum in das Burgenland ausgedehnt und umfasst das urbanisierte Industriegebiet Mattersburg - Neudörfl - Hornstein (Nr. 63) sowie daran angrenzend das Zentrum Eisenstadt (Nr. 61). Es bedürfte einer speziellen Untersuchung, um zu klären, ob die Neuindustrialisierung bzw. Verlagerung von Industrien in das Burgenland bereits auf die seit 1995 wirksame Ziel-1-Förderung seitens der EU zurückzuführen ist. Trotzdem weist auch das Mattersburger Gebiet, ebenso wie die vorgenannten Gebiete des Typs II und III, ein deutliches Arbeitsplatzdefizit auf. Das frühere Menggebiet im mittleren Wiener Becken ist zu einem dienstleistungsbetonten Wohngebiet (Typ IVe_w, Nr. 13) geworden; ebenso das ehemalige Industriegebiet im östlichen Wiener Becken (Nr. 14), das wegen der fehlenden räumlichen Anbindung an das Hauptregionszentrum nach BoBEKs Kriterium (vgl. oben 2.3.2) nicht mehr Teil des wirtschaftsstrukturellen Zentralraums ist.

Im Westen und Nordosten des Wiener Zentralraums erstrecken sich urbanisierte Dienstleistungsgebiete (Typ VII), meist mit Wohncharakter; der Wienerwald (Nr. 2 a, b) war bereits 1971 ein Wohngebiet (des Typs IVe_w). Im NO Wiens ist der Wohncharakter vor allem entlang der Nordbahn (Nr. 54) ausgeprägt, das übrige nordwestliche Marchfeld (Nr. 53) hat ebenfalls Typ VII, ist aber relativ stark industrialisiert. Im Norden endet der Wiener Zentralraum ebenso wie 1971 mit den zwei Sekundärzentren Korneuburg und Stockerau (Nr. 52, 51).

Der Linzer Zentralraum ist ähnlich vielfältig wie der Wiener Zentralraum (vgl. Abb. 8). Der Strukturtyp hat sich seit 1971 zwar fast überall geändert, aber insgesamt hat der oberösterreichische Zentralraum den industriellen Charakter viel stärker bewahrt.

Linz (früher Typ II) ist nun wie alle anderen Hauptregionszentren ein überwiegendes Dienstleistungszentrum (Typ I, Gebiet Nr. 129), allerdings vom Subtyp Z(i), mit

\footnotetext{
5) Die in diesem Abschnitt angeführten Strukturgebietsnummern beziehen sich durchwegs auf die neue Karte (Stand 2001)
} 


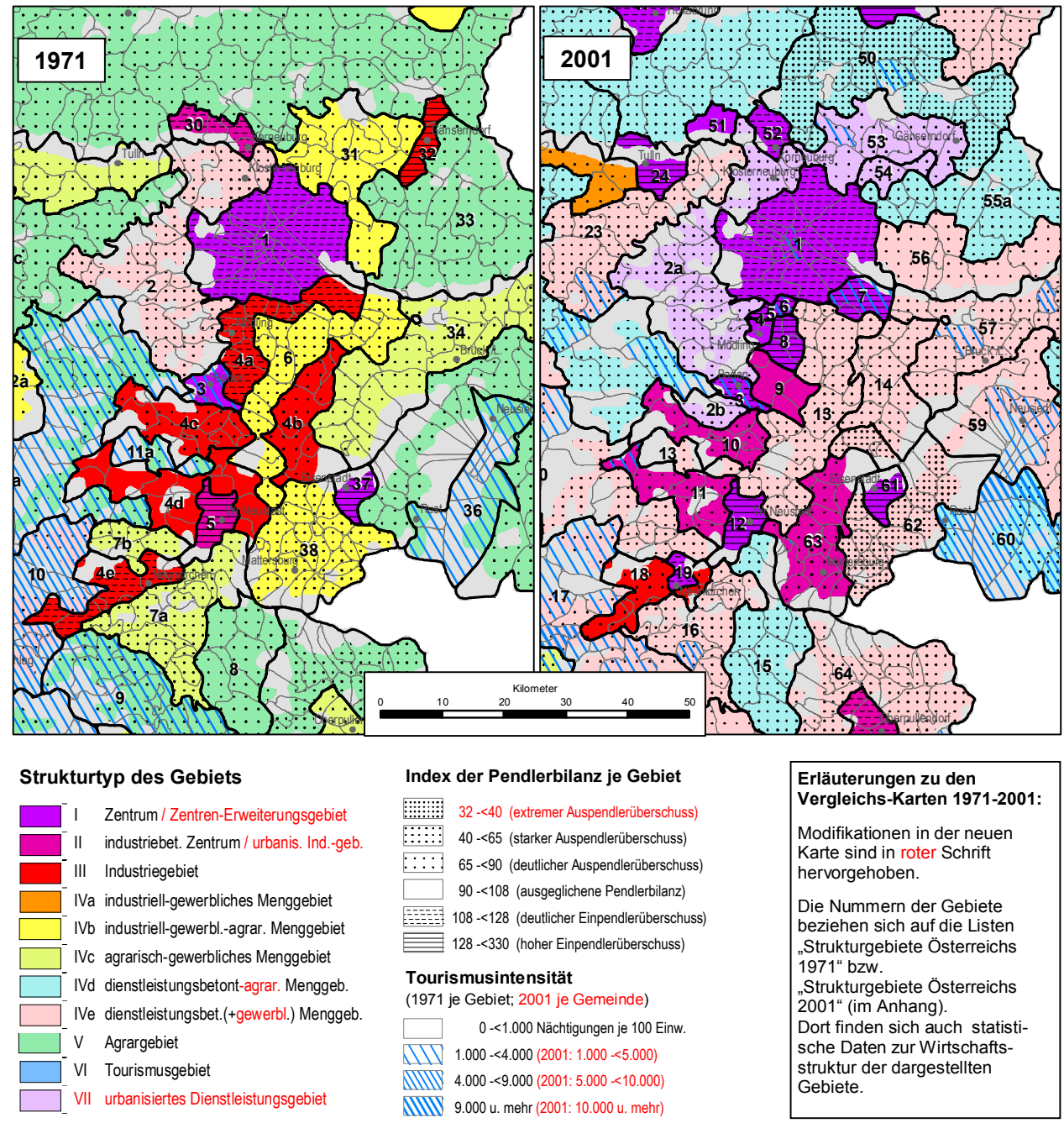

Quelle: Bobeк \& HofmaYer 1979; Kulmhofer 2009 (geringfügig modifiziert).

Abb. 7: Strukturgebietsgefüge des Wiener Zentralraums 1971 und 2001

ca. 28.000 Industriebeschäftigten. Im übrigen Zentralraum haben sich die ehemaligen Industriegebiete zwar strukturell transformiert, aber flächenmäßig ausgedehnt: Die industriebetonte Struktur des Traun-Ager-Tales erstreckt sich 2001 im Alpenvorland bis Vorchdorf (Nr. 135); das Gebiet beherbergt mit über 15.000 die meisten Industriebeschäftigen aller Typ II-Gebiete Österreichs und weist sogar Arbeitsplatzüberschuss auf. Im Osten des Zentralraums hat sich die industriell-gewerbliche Mengstruktur über Perg hinaus ins untere Mühlviertel ausgedehnt (Typ IVa, Nr. 113). Zwischen Linz und dem großen Sekundärzentrum Wels (Nr. 134) transformierte sich das frühere Industrie- und Wohngebiet (mit starkem Auspendlerüberschuss) in ein HauptzentrumsErweiterungsgebiet (Nr. 133, mit Einpendlerüberschuss), das mit knapp 42.000 Ar- 

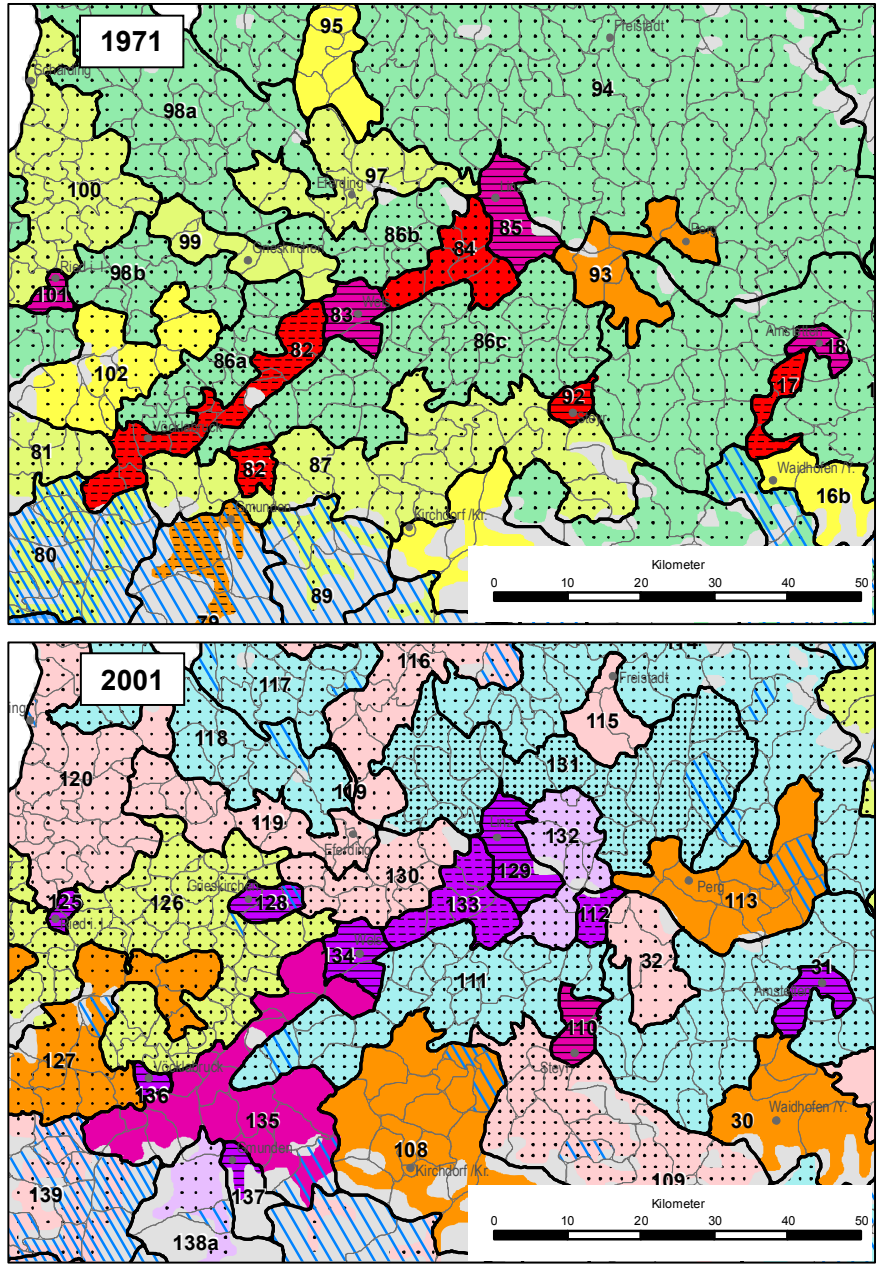

Strukturtyp des Gebiets

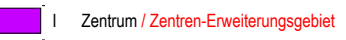

industriebet. Zentrum / urbanis. Ind.-geb.

III Industriegebiet

IVa industriell-gewerbliches Menggebiet

IVb industriell-gewerbl-agrar. Menggebiet IVc agrarisch-gewerbliches Menggebiet IVd dienstleistungsbetont-agrar. Menggeb. IVe dienstleistungsbet.(+gewerbl.) Menggeb. Agrargebiet VI Tourismusgebiet VII urbanisiertes Dienstleistungsgebiet

Index der Pendlerbilanz je Gebiet $32<40$ (extremer Auspendlerüberschuss) $40-<65$ (starker Auspendlerüberschuss) $65<90$ (deutlicher Auspendlerüberschuss) $90-<108$ (ausgeglichene Pendlerbilanz) $108-<128$ (deutlicher Einpendlerüberschuss) $128<330$ (hoher Einpendlerüberschuss) Tourismusintensität (1971 je Gebiet; 2001 je Gemeinde) $0-<1.000$ Nächtigungen je 100 Einw. $1.000<4.000(2001: 1.000<5.000)$ $4.000<<9.000(2001: 5.000<10.000)$ NIIV 9.000 u. mehr (2001: 10.000 u. mehr)

Quelle: Bobek \& Hofmayer 1979; Kulmhofer 2009 (geringfügig modifiziert).

Abb. 8: Strukturgebietsgefüge des Linzer Zentralraums 1971 und 2001

beitsplätzen, davon 9.500 in der Industrie, den suburbanen Zentren südlich von Wien ebenbürtig ist.

Ein urbanisiertes Wohngebiet (Nr. 132, Typ VII) umgibt Linz halbkreisförmig im Osten, nördlich der Donau grenzt ein noch eher ländliches Wohngebiet des Typs IVd_w (Nr. 131, mit extremem Auspendlerüberschuss) an. Als neue Sekundärzentren des Zentralraums heben sich Vöcklabruck (Nr. 136) und Enns (Nr. 112) heraus, auch Gmunden (Nr. 137) ist nun an den Zentralraum angebunden.

Eine Erklärung der unterschiedlichen sektoralen Entwicklung der beiden Zentralräume geht über den Rahmen dieses Beitrags hinaus. Ansätze hierzu bieten möglicherweise Unterschiede in der Eigentümerstruktur der Industrie (Verstaatlichten-Anteil) und in der Entfernung vom Hauptmarkt Deutschland. 


\subsubsection{Beispiele zur Entwicklung ehemaliger Agrarräume: Vergleich Waldviertel - oststeirisches Hügelland/Südburgenland}

Die genannten Gebiete gehörten 1971 zu den größten dominant agrarischen Räumen Österreichs. Im Waldviertel herrschte, abgesehen von seinem altindustrialisierten Nordwestteil, eine eher extensive Agrar- und Forstwirtschaft vor, in der Oststeiermark - mit Ausnahme einiger industrialisierter „Inseln“ (Weiz, Feldbach, Fürstenfeld) arbeitsintensive Acker-, Vieh- und Obstwirtschaften; im Südburgenland überwogen kleinflächige Nebenerwerbsbetriebe, die Industrie war nur im Pinkatal gebietsprägend. Der Fremdenverkehr trat auf Gebietsebene nirgends in Erscheinung, er beschränkte sich auf isolierte Erholungsgemeinden an Stauseen (Ottenstein bzw. Stubenberg) und wenige traditionelle Thermalkurorte (Bad Gleichenberg, Bad Tatzmannsdorf). Da die zentralen Orte nur wenige Arbeitsplätze boten, gab es 1971 in diesen Agrarräumen kein einziges Sekundärzentrum (vgl. Abb. 9 und 10).

Zum Zeitpunkt 2001 präsentieren sich beide Gebiete stark verändert, wobei sowohl Gemeinsamkeiten als auch regionale Sonderentwicklungen zu beobachten sind.

Der Agrarcharakter hat sich am ehesten in der Oststeiermark erhalten, wo die Struktur eines agrarisch-gewerblichen Menggebiets (IVc, Gebiet Nr. 71) großflächig an die Stelle der Agrardominanz trat. Im Südburgenland ging der Agrarcharakter weitgehend verloren, es überwiegen dienstleistungsbetonte Menggebiete des Typs IVe (Nr. 67a,b,c); die verstreuten Restgebiete dienstleistungs-agrarischer Struktur (IVd, Nr. 68) weisen trotz der großen Entfernung von Arbeitszentren extremen Auspendlerüberschuss auf. Im Waldviertel ist der Agraranteil im Südteil noch am stärksten erhalten (IVc, Nr. 37), im mittleren und östlichen Waldviertel herrschen dienstleistungs-agrarische Menggebiete (IVd, Nr. 40a,b) vor.

Die Industrie im Waldviertel ist im früher dominanten Gebiet Gmünd - Heidenreichstein stark zurückgegangen; in den angrenzenden Bezirken Waidhofen an der Thaya und Zwettl konnte sie dank einiger Neugründungen ihren Beschäftigtenstand fast halten; rund um die beiden Bezirksstädte entstanden IVe-Gebiete mit ausgeglichener bzw. positiver Pendlerbilanz (Nr. 43, 38). Das auf der Karte dargestellte Industriegebiet Schrems - Vitis (Nr. 42) erreichte 2001 nur knapp die Mindestgröße und hat seither an Beschäftigten verloren, sodass es heute nicht mehr als solches abgegrenzt werden könnte. In der Oststeiermark hingegen entstand ein neues urbanisiertes Industriegebiet (Typ II, Nr. 85) im Raabtal um Gleisdorf, das sich in einem ebenfalls industrialisierten dienstleistungs-gewerblichen Menggebiet (Typ IVe, Nr. 83) entlang der Südautobahn bis Graz fortsetzt. Diese zwei Gebiete zählen nunmehr zusammen mit dem älteren Industriestandort Weiz (Nr. 84) zum Zentralraum von Graz. Darüber hinaus wurden an verschiedenen Orten der Ost- wie auch der Weststeiermark mittlere und kleine Betriebe der Autozulieferbranche gegründet, die unter dem Dach des „Autocluster Styria“ kooperieren. Eine solche Initiative besteht im Waldviertel nicht. Im Südburgenland wurden zwar einzelne Industriebetriebe gegründet (am bekanntesten das Lenzing-Werk in Heiligenkreuz im Lafnitztal), insgesamt ist jedoch die Zahl der Industriearbeitsplätze dort zurückgegangen; die Regionalförderungen seitens Österreichs und die EU-Fördermittel wurden überwiegend in Umwelt- und Tourismusprojekte geleitet. 


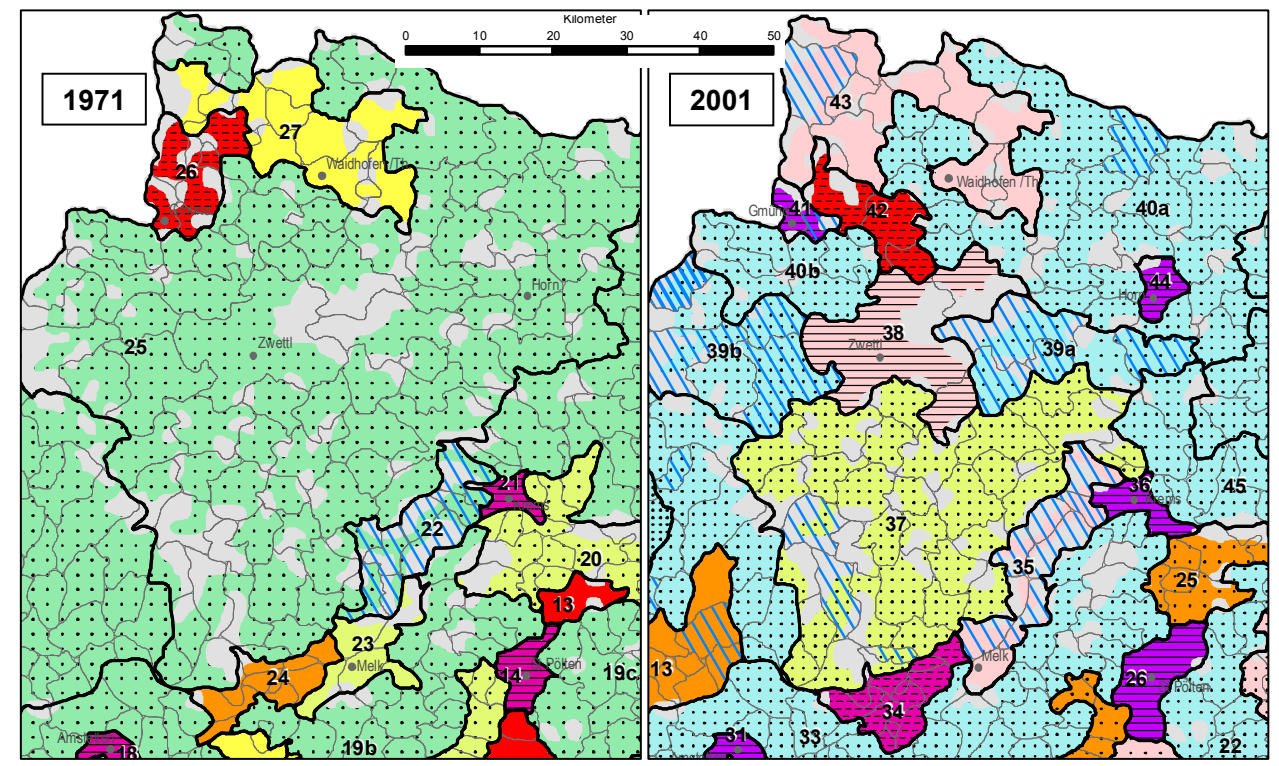

Quellen: BobeK \& HofMAYer 1979; KULMHOFER 2009 (geringfügig modifiziert). Legende vgl. Abb. 7 und 8. Zur Vervollständigung der Information sei auf die statistischen Daten auf den Gebietslisten im Anhang verwiesen, insbesondere auf die Arbeitsplatzausstattung (Arbeitsbevölkerung).

Abb. 9: Strukturgebietsgefüge des Waldviertels 1971 und 2001

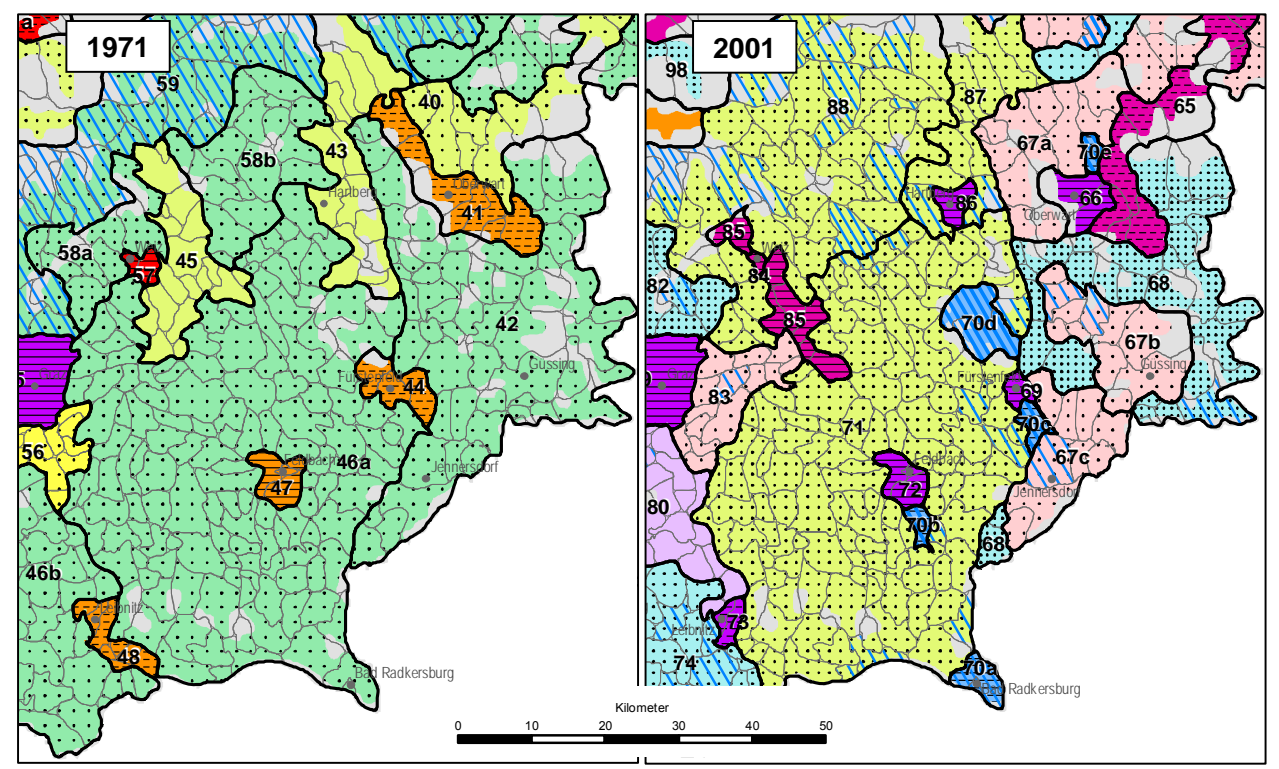

Quellen: BobeK \& HofMAYeR 1979; KulMHOFER 2009 (geringfügig modifiziert)

Abb. 10: Strukturgebietsgefüge der Oststeiermark und des Südburgenlands 1971 und 2001 
Die Versorgungs-Dienstleistungen erlebten in beiden hier betrachteten Räumen eine starke Zunahme, die sich auf die Bezirkshauptorte konzentrierte, sodass viele von ihnen 2001 als Zentren-Strukturgebiete auszusondern waren. Das stärkste Arbeitsplatzwachstum erfuhren die oststeirischen Zentren Hartberg (Nr. 86), Feldbach (Nr. 72) und Fürstenfeld (Nr. 69) sowie Oberwart (Nr. 66) im Burgenland. Im Waldviertel erreichten Gmünd (Nr. 41) und Horn (Nr. 44) als Zentren die Größenschwelle von Strukturgebieten, allerdings nur ganz knapp.

Bei den touristischen Dienstleistungen ergab sich durch die Innovation und Diffusion des Gesundheits- und Wellnesstourismus eine regionale Sonderentwicklung in Südostösterreich. An zahlreichen Orten der Oststeiermark und des Südburgenlands wurde - häufig im Zuge von Erdöl- oder Erdgasprospektion - Thermalwasser erbohrt, was in mehreren Fällen zur Entwicklung von Thermen-Ressorts führte. Da eine entsprechende Nachfrage gegeben war, entstand ein lukrativer Ganzjahrestourismus. Auf der Karte von 2001 sind folgende Thermendestinationen mit tourismusdominanten Strukturen ausgewiesen: Bad Radkersburg (Nr. 70a), Loipersdorf bei Fürstenfeld (Nr. 70c) und Bad Waltersdorf - Bad Blumau (Nr. 70d); sie bilden zusammen mit den älteren Kurorten Bad Gleichenberg (Nr. 70b) und Bad Tatzmannsdorf (Nr. 70e) das neue Tourismusgebiet „Kur- und Thermengemeinden der Oststeiermark und des Südburgenlands“. 6 .

Das Waldviertel hat hingegen von dieser Innovation bis 2001 kaum profitiert. Die neuere Tourismusentwicklung beschränkt sich auf wenige Standorte des Gesundheitstourismus: Die kleine Gemeinde Moorbad Harbach überschreitet als einzige in Niederösterreich eine Intensität von 10.000 Übernachtungen je 100 Einwohner. Harbach mit Groß Gerungs (Rehabilitationszentrum) und einige Gemeinden im mittleren Kamptal bilden ein zweigeteiltes Menggebiet mit mäßiger Tourismusintensität (Nr. 39a, b). Weitere Gemeinden mäßiger Intensität gibt es im Südwesten und Norden des Waldviertels. Ähnliche Formen und Intensitäten eines einsaisonalen Tourismus trifft man auch in einzelnen Gemeinden der Oststeiermark, vor allem in der Umgebung von Hartberg.

\subsubsection{Beispiele zur Entwicklung von Tourismusräumen: Vergleich hochalpines Salzburg - Kärnten}

Nicht zuletzt wegen der Bedeutung des Fremdenverkehrs für die österreichische Volkswirtschaft sollen auch zwei Beispielsräume mit mehr oder minder intensivem Tourismus vorgestellt werden. Salzburg ist nach Tirol das Bundesland mit der höchsten Übernachtungsintensität, auch dank der doppelten Saison. Kärnten hingegen ist vor allem durch seine Seen als Sommerurlaubsdestination seit Generationen bekannt. Diese beiden Räume sollen in einem Längs- und Querschnitt ihres Strukturgebietsgefüges vergleichend analysiert werden.

\footnotetext{
6) Eine derartige Zusammenfassung von fünf nicht aneinandergrenzenden Teilgebieten zu einem Strukturgebiet entspricht an sich nicht dem Prinzip der geographischen Regionalisierung, weil keine räumliche Kontingenz gegeben ist. Allerdings handelt es sich um eine klar definierte Wirtschaftsstruktur, die in sehr ähnlicher Weise an mehreren Standorten in geringer Entfernung voneinander auftritt. Für solche Situationen wurde von Bobek \& Hofmayer (1981, S. 31f.) eine Ausgliederung und Zusammenfassung von Teilgebieten vorgesehen (vgl. oben, 2.2, die Ausführungen über Mindestgröße eines Strukturgebiets).
} 
Im Land Salzburg stellte sich zum Zeitpunkt 1971 die Raumstruktur unter besonderer Berücksichtigung des Tourismus etwa so dar (vgl. Abb. 11): Mit Ausnahme eines kleinen Gebietes nördlich von Salzburg (westlicher Flachgau) wiesen alle Strukturgebiete mindestens mäßige Tourismusintensität auf: Selbst die Landeshauptstadt erreichte mehr als 1.000 Nächtigungen je 100 Einwohner, ähnlich die Wohngebiete in ihrer Umgebung und auch die industriellen Gebiete an der Hauptverkehrsachse im Salzachtal von Hallein bis St. Johann im Pongau. Starke Tourismusintensität $(>4.000$ Nächtigungen) besaßen die damals noch bestehenden Agrargebiete in Seitentälern des Salzachtals sowie die Menggebiete in breiteren Becken und Tälern der Hochalpen

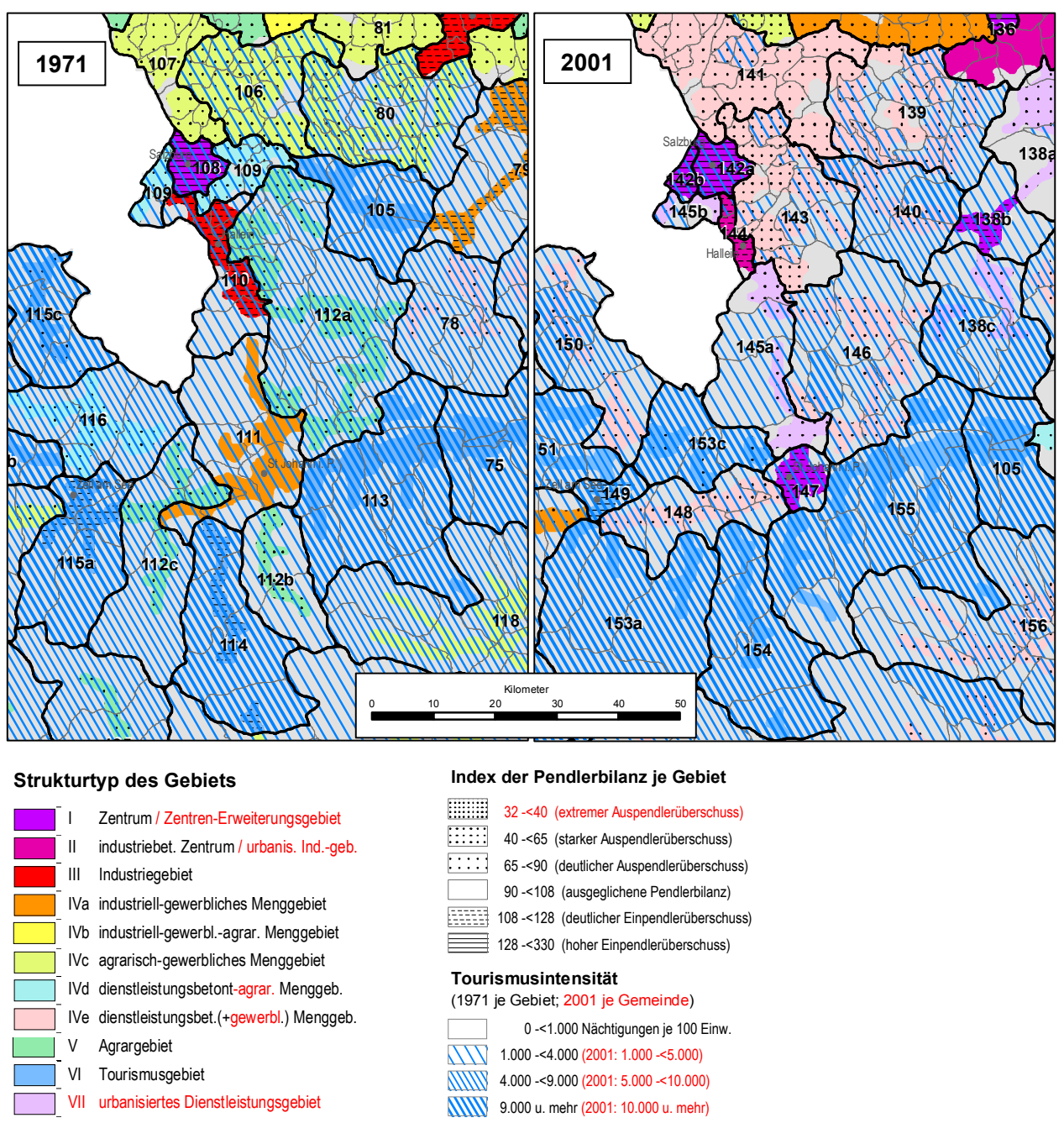

Quellen: BobeK \& HofmaYer 1979; Kulmhofer 2009 (geringfügig modifiziert)

Abb. 11: Strukturgebietsgefüge im Land Salzburg 1971 und 2001 
(Saalfelden, Oberpinzgau, Lungau). Dominant war der Tourismus im alterschlossenen Gasteinertal (inklusive Mallnitz, Kärnten), in den zentralalpinen Schigebieten von Zell am See und Kaprun, von Saalbach und von Altenmarkt - Radstadt - Obertauern, sowie in den Gebieten von Lofer und Wolfgangsee/Fuschlsee.

30 Jahre später hat sich der Strukturtyp in allen Landesteilen mit Ausnahme der dominanten Tourismusgebiete verändert. Im Landesdurchschnitt hat sich der Tourismus intensiviert und ausgedehnt, ist aber - gemessen am Nächtigungsverkehr - in manchen Gebieten auch zurückgegangen. Im zentralalpinen Salzburg hat der Intensivtourismus nunmehr auch die vorher agrarischen Seitentäler erfasst (Kleinarltal: Teil von Gebiet Nr. 155; Rauris: Teil von 153a; Dienten am Hochkönig: Teil von 153c), sodass praktisch der gesamte Süden des Landes - außer dem Salzachtal und dem Lungau - von Intensivtourismusgebieten eingenommen wird. Etwa gleich geblieben ist die Tourismusintensität nur im mittleren Oberpinzgau und im Lungau (Nr. 156). Im Kalkalpenraum kam es zu einer Abnahme der Intensität in den Gebieten von Lofer und Saalfelden (Nr. 150).

Die Landeshauptstadt Salzburg (Nr. 142) konnte ihre Übernachtungsintensität auf dem erwähnten, für Großstädte sehr hohen Niveau halten. Im Voralpenbereich sank die Intensität im Umland von Salzburg (Nr. 143, 144), im mittleren und östlichen Flachgau (Nr. 141) und am Wolfgangsee (Nr. 140). Die Abnahme der Übernachtungsintensität ist allerdings oft nur eine rechnerische Konsequenz der starken Bevölkerungszunahme im Stadtumland, verbunden mit zunehmendem Zweitwohnungswesen. In landschaftlich besonders attraktiven Gebieten, wie am Wolfgangsee, schafft der rege Ausflugsverkehr aus Ballungsgebieten Oberösterreichs und Bayerns einen gewissen Ausgleich für Nächtigungsrückgänge.

Im dargestellten mittleren Teil Kärntens (vgl. Abb. 12) gab es zum Zeitpunkt 1971 an allen Badeseen dominante Fremdenverkehrsgebiete: sowohl im Oberkärntner Raum (Weißensee, Millstätter See, Afritzer Seen mit Bad Kleinkirchheim) als auch an den Mittelkärntner Seen (Ossiacher, Wörther- und Klopeiner See). In den übrigen Gebieten Ober- und Mittelkärntens war der Fremdenverkehr in mäßiger Intensität vertreten (im Zentrum Villach, im mittleren Drau- und Rosental und in den westlichen Gurktaler Alpen), im Gailtal und im damals noch ausgesonderten kleinen Radentheiner Bergbaugebiet sogar in starker Intensität.

Betrachtet man die Situation 2001, so fällt zunächst die Konstanz des Wirtschaftsstrukturtyps IVa auf: Industriell-gewerbliche Strukturen blieben im Raum Althofen - Görtschitztal (Nr. 159) und im mittleren Drautal (Nr. 169) über 30 Jahre hinweg erhalten. Hinsichtlich Tourismusintensität zeigt sich in Kärnten eine Abnahme: Die Intensivgebiete haben sich in Summe verkleinert, eklatante Rückgänge von dominanter zu mäßiger Tourismusintensität gab es im Afritzer Seengebiet in Oberkärnten (zwischen Nr. 158 und 164a) sowie am Wörthersee-Westufer um Velden (Nr. 167b, nunmehr urbanisiertes Dienstleistungsgebiet). Auch im oberen Drau- und Mölltal ist der vorher nur mäßige Tourismus weiter zurückgegangen. Zunahmen der Intensität gab es nur in einzelnen hochalpinen Gemeinden (Rennweg am Katschberg und Heiligenblut am Großglockner), wo es gelang, die Wintersaison auszubauen.

Das Zentrum Villach (Nr. 168) konnte seine mäßige Tourismusintensität dank des Kur- und Rehabilitationsbetriebs halten. Als einziges Zunahmegebiet des Tourismus erscheint das vergrößerte Intensivgebiet Hermagor - Weißensee (Nr. 171), wo die 


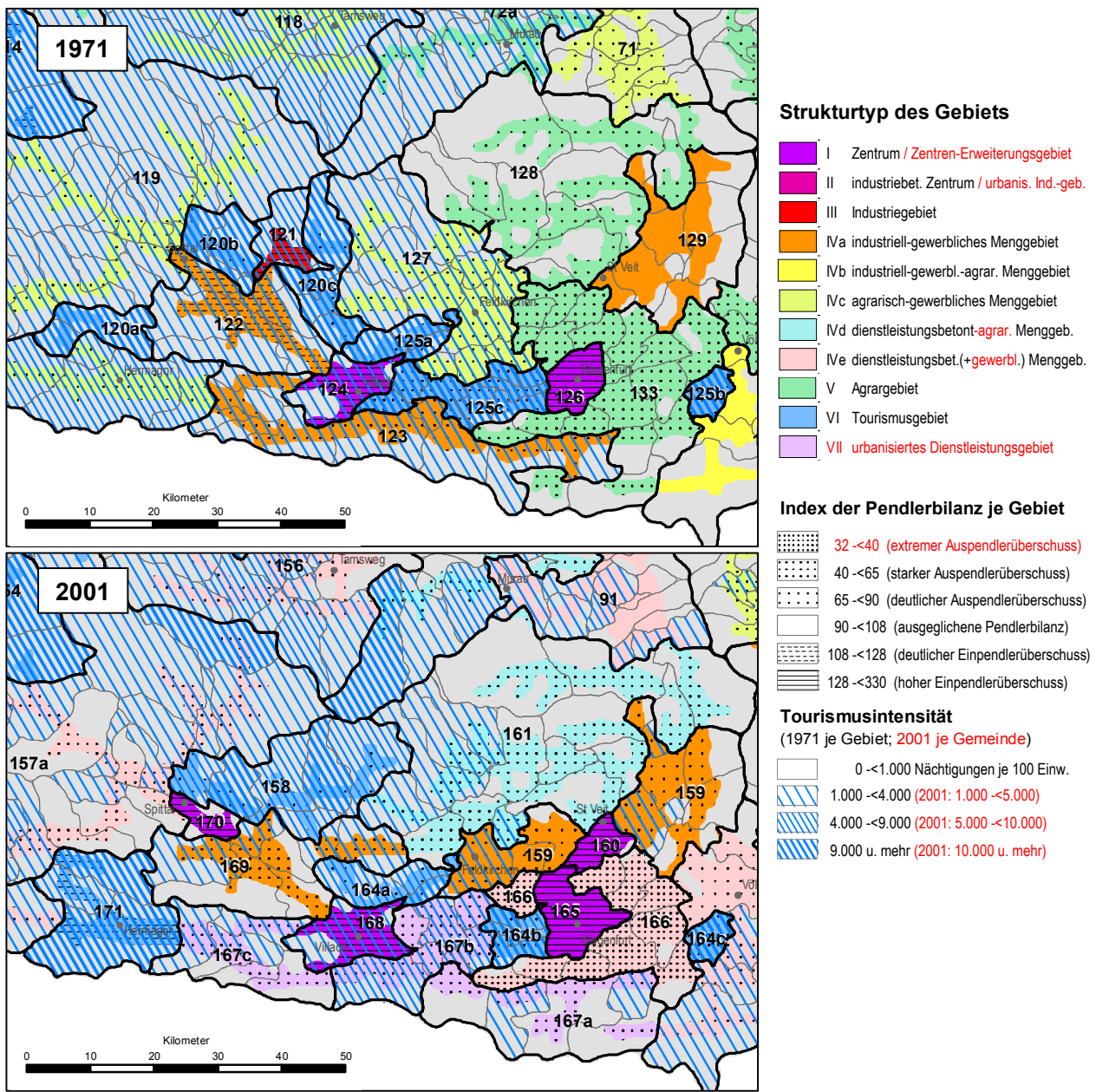

Quellen: Bobek \& Hofmayer 1979; Kulmhofer 2009

Abb. 12: Strukturgebietsgefüge im zentralen Teil Kärntens 1971 und 2001

Nächtigungen absolut gestiegen sind. Hauptgrund dafür ist die Entwicklung des Schitourismus auf dem Nassfeld.

Die Unterschiede der Tourismusentwicklung zwischen den beiden Ländern sind eklatant: gebietliche Ausweitung und Intensivierung in Salzburg, räumliche Schrumpfung und Extensivierung in Kärnten. Ein ähnlicher Abstieg ehemaliger Intensivtourismusgebiete wird in der Dissertation auch in anderen Fällen konstatiert. Eine Erklärung hierfür bietet das Phasenmodell des touristischen Lebenszyklus von R. ButLER (1980): „Die Rejuvenation ist vor allem in traditionellen Sommerfrischengebieten in der Osthälfte Österreichs (östlich der Linie Linz - Kärnten) nicht gelungen. Die veränderten Urlaubsgewohnheiten des ehemaligen Stammpublikums - mehr und günstigere Fernreisen - haben dazu beigetragen.“ (KULMHOFER 2009, S. 267) 


\section{Resümee: Wichtigste Ergebnisse der vorliegenden Raumgliederung}

Die in diesem Beitrag vorgestellte neue wirtschaftsräumliche Gliederung Österreichs weist nach, dass das von Bовек zum Stand 1971 abgeleitete dichotome Raummodell (,Zentralraum/Peripherie“) im Wesentlichen weiter besteht. Konkret umfasst das wirtschaftsstrukturelle Raummodell zum Stand 2001 folgende Gebietskategorien:

- Zentralraum mit intensivem Wirtschaftscharakter, d.h. hoher Arbeitsplatzdichte;

- Peripherie mit extensivem Charakter, aber mehr eingestreuten „Intensivinseln“ als 1971.

Im Zuge der Aktualisierung des Modells werden in beiden Raumkategorien für 2001 zwar überwiegend dieselben Strukturtypen wie 1971, aber auch einige neu hinzugekommene Typen identifiziert. Die wesentlichen Veränderungen des neuen Raummodells gegenüber 1971 sind:

- im Zentralraum: starke Reduktion industriegeprägter Strukturgebiete; Entstehung des neuen Strukturtyps „suburbane Dienstleistungsgebiete“ angrenzend an große Zentren; Ausdehnung der Wohngebiete;

- in der Peripherie: starke Vermehrung von sekundären Zentren; Wandlung der früheren Agrarperipherie in eine Meng-Peripherie (völliges Verschwinden der Agrargebiete und auch der industriell-gewerblich-agrarischen Menggebiete); Vermehrung dienstleistungsbetonter Menggebiete.

Die Ergebnisse bezüglich der sektoralen Transformation stehen im Einklang mit theoretischen Aussagen über den sektoralen Wandel entwickelter Volkswirtschaften Stichworte: Deagrarisierung, Deindustralisierung und Tertiärisierung. Konkret liefert die neue Regionalisierung folgende Erkenntnisse über die strukturelle Transformation der Gebiete im Zeitraum 1971 bis 2001 (vgl. Kulmhofer 2009):

- Entwicklung der Gebiete ehemals vorherrschenden Primärsektors:

- Die ehemaligen Agrargebiete haben sich zu Menggebieten verschiedenen Typs gewandelt.

- Die Basishypothese einer flächendeckenden Deagrarisierung (Abnahme der Agrarbeschäftigten in allen Teilen Österreichs in etwa gleichem Ausmaß) wird im Wesentlichen bestätigt.

- Allerdings wird eine verstärkte Deagrarisierung in den Gebieten entlang der Ostgrenze im Jahrzehnt nach der Ostöffnung (1991-2001) konstatiert.

- Entwicklung der Gebiete ehemals vorherrschenden Sekundärsektors:

- Die zahlreichen Industriegebiete von 1971 haben bis 2001 mit Ausnahme von drei Reliktgebieten (zwei in NÖ, eines in Tirol) ihre Industriedominanz verloren. Die meisten transformierten sich zu dienstleistungsbetonten Strukturgebieten (Zentren oder industriebetonte Zentren bzw. urbanisierte Industriegebiete).

- Der Großteil der Industriebeschäftigten Österreichs ist nunmehr in dienstleistungsbetonten Strukturgebieten (vor allem des Typs I, „Zentren“) tätig.

- Parallel dazu kam es aber auch zu einem Vordringen der Industrie in bisher ländliche Gebiete. Dies ist vor allem in den Ländern Oberösterreich und Steiermark zu 
beobachten, wo Gebiete der Typen IVa (industriell-gewerbliche Menggebiete) bzw. II (Subtyp urbanisierte Industriegebiete) sich ausgedehnt haben. Häufig handelt es sich um neue bzw. vergrößerte Betriebe der Autozulieferindustrie, welche im Rahmen von „Auto-Clustern“ kooperieren.

- In allen Gebieten mit schon 1971 vorherrschendem Tertiärsektor hat es eine weitere Verstärkung des Dienstleistungssektors gegeben. Dabei ist zwischen städtischen Zentren und Tourismusgebieten zu unterscheiden.

- Bei den städtischen Zentren werden folgende Veränderungen festgestellt:

- Die Zahl der Strukturgebiete des Typs „Zentrum“ hat sich exponentiell vermehrt (1971: 11; 2001: 62; die Mehrzahl der Bezirkshauptorte bildet nun ein Gebiet dieses Typs), was auf die Tertiärisierung der Gesamtwirtschaft zurückgeführt wird.

- Dienstleistungsbetonte Strukturen haben sich aus den größeren städtischen Zentren in deren nahes Umland ausgeweitet, wo der erwähnte neue Strukturtyp „urbanisierte Dienstleistungsgebiete“ (Typ VII) mit ganz ähnlicher Sektoralstruktur der Beschäftigten wie in Zentren, aber ohne Einpendlerüberschuss, entstand.

- Im Suburbanisationsraum der größten Hauptregionszentren (Wien, Linz, Salzburg, in Ansätzen auch bei Graz) entstanden aufgrund derselben Tendenz sogar „Hauptzentrums-Erweiterungsgebiete“ in dem Sinn, dass einzelne oder mehrere benachbarte Gemeinden den gleichen Strukturtyp I wie die Zentren (mit der geforderten Mindestgröße und mit Einpendlerüberschuss) aufweisen.

- Die Branchenstruktur dieser neu entstandenen Zentren bzw. Zentrengebiete im Stadtumland unterscheidet sich von jener der ,alten“ Zentren (Landes-, Viertels- und Bezirkshauptstädte) dadurch, dass erstere einen höheren Anteil an produktionsnahen Dienstleistungen (,Advanced Producer Services') besitzen.

- Bei den Tourismusgebieten kam es zu folgenden Entwicklungen:

- Die meisten der 1971 bestehenden Intensivgebiete haben diesen Strukturtyp beibehalten, indem dort weitere Intensivierungen durch entsprechende Investitionen stattfanden.

- Durch Diffusion des Wellness- und Gesundheitstourismus entstand in Südostösterreich ein neues, mehrteiliges Intensivtourismusgebiet (Oststeirische Thermenregion mit Ausläufern im Burgenland); in anderen ländlichen Gebieten - wie dem Waldviertel - führte derselbe Trend bis 2001 nur zu erhöhter Tourismusintensität in Menggebieten (ehemaligen Agrargebieten).

- Einige traditionsreiche Fremdenverkehrsgebiete haben einen Niedergang des (Übernachtungs-)Tourismus bzw. eine Umwandlung zu Zweitwohngebieten erlebt; sie liegen ausschließlich in der Osthälfte Österreichs (Wolfgangsee, Mariazell, Mitterndorf-Tauplitz, Wörthersee).

Abschließend: Die neue Regionalisierung ermöglicht - im Vergleich mit der vor 30 Jahren erschienenen Karte - vertiefte Einsichten in die standörtliche Dynamik der Wirtschaft und in den Lebenszyklus von Regionen. Zur Visualisierung der Entwicklung erscheint die angewandte Methode des Vergleichs intertemporaler Kartenpaare durchaus geeignet. 
Die hier vorgestellten Ergebnisse machen klar, dass die Raumstruktur der Wirtschaft Österreichs nur auf der obersten räumlichen Ebene (jener der Hauptregionen) über einen längeren Zeitraum fast konstant ist. Auf der kleinräumigen Ebene unterliegt sie permanenten Veränderungen. Eine laufende Aktualisierung erscheint hier notwendig. Hierfür bietet sich die im Jahr 2011 durchgeführte Volkszählung an .

\section{Literaturverzeichnis}

B ARTels D. (1975), Die Abgrenzung von Planungsregionen in der Bundesrepublik Deutschland - eine Operationalisierungsaufgabe. In: Ausgeglichene Funktionsräume - Grundlagen für eine Regionalpolitik des mittleren Weges (= Forschungs- u. Sitzungsberichte, 94, Veröff. d. ARL), S. 93-115. Hannover, Hermann Schroedel Verlag.

Birner A., Schremmer C., Tödtling F. (1997), Die neue Industrielandschaft Österreichs. Forschungsbericht. Wien, ÖIR.

Вовек H. (1981), Abschnitte „4.3.1. Die Standortstendenzen der verschiedenen Wirtschaftssektoren“ und „4.3.2. Das Modell der räumlichen Verteilung der wirtschaftlichen Strukturgebiete“. In: Boвeк H., Hofmayer A., Gliederung Österreichs in wirtschaftliche Strukturgebiete (= Beiträge z. Regionalforschung, 3), S. 76-87. Wien, Verlag d. ÖAW.

Bobex H., Hofmayer A. (1979), Karte „Wirtschaftliche Strukturgebiete auf Grund der Arbeitsbevölkerung und Pendlerbilanz“ 1:1,000.000. In: ÖAW (Hrsg.), Atlas der Republik Österreich, 6. Lfg., Wien, XII/5.

Bobeк H., HofmaYer A. (1981), Gliederung Österreichs in wirtschaftliche Strukturgebiete (= Beiträge z. Regionalforschung, 3). Wien, Verlag d. ÖAW.

Вовек Н., SтеINBACH J. (1970), Karte „Wirtschaftsräumliche Gliederung Österreichs 1:1,000.000“. In: Strukturanalyse des österreichischen Bundesgebietes, III (= Schriftenreihe d. Österr. Ges. f. Raumforschung u. Raumplanung). Wien.

ButLER R. (1980), The Concept of a Tourist Area Cycle of Evolution. Implications for Management of Resources. In: Canadian Geographer, 24, 1, S. 5-12.

JohNSTON R.J. (1970), Grouping and regionalizing: some methodological and technical observations. In: Economic Geography, 46, S. 293-305.

Kulmhofer H. (2009), Die kleinräumige sektorale Standortstruktur der österreichischen Wirtschaft 2001 im Vergleich mit 1971. Wien, Diss., Wirtschaftsuniv. Wien.

MaYerhofer P. (1999), Räumliche Effekte des Strukturwandels - Stadtregionen als Gewinner der Tertiärisierung? Studie des Österreichischen Instituts für Wirtschaftsforschung [WIFO] im Auftrag der Kammer für Arbeiter und Angestellte für Wien, Wien.

Openshaw S., Wymer C. (1995), Classifying and regionalizing census data. In: Openshaw S. (Hrsg.), Census Users'Handbook, S. 239-269. Cambridge, Geoinformation International.

ÖsterREICHISCHE RAUMORDNUnGSKONFERENZ [ÖROK] (Hrsg.) (2004), Kartentafel „Veränderung der regionalen Wirtschaftsstruktur 1971-2001“. In: Atlas zur räumlichen Entwicklung Österreichs, Wien, Blatt 02.03.07/2004.

Sedlacek P. (Hrsg.) (1978), Regionalisierungsverfahren (= Wege der Forschung, CXCV). Darmstadt, Wiss. Buchges.

SinTon D.F. (1978), The inherent structure of information as a constraint to analysis: mapped thematic data as a case study. In: Dutton G. (Hrsg.), Harvard Papers on Geographic Information Systems (Proc. of the first Intern. Symp. on Topological Data Structures for Geographic Information Systems), 7, S. 1-17. Reading, MA, Addison-Wesley.

STÖHR W. (1983), Buchbesprechung von Bobek \& Hofmayer (1981, a.a.O.). In: Mitt. d. Österr. Geogr. Ges., 125, S. 279-280. 